1 Spectral efficiencies of carbon monoxide photoproduction from particulate and

\section{Guisheng Song ${ }^{\mathrm{a}, \mathrm{b}}$, Huixiang Xie $\mathrm{X}^{\mathrm{b}, *}$} Rimouski, Québec G5L 3A1, Canada

\section{ABSTRACT}

\title{
dissolved organic matter in laboratory cultures of Arctic sea ice algae
}

${ }^{\mathrm{a} C}$ College of Marine and Environmental Sciences, Tianjin University of Science and Technology, $2913^{\text {th }}$ Avenue, TEDA, Tianjin, 300457, P.R. China

${ }^{\mathrm{b}}$ Institut des sciences de la mer de Rimouski, Université du Québec à Rimouski,

* Corresponding author. Tel.: +1 418723 1986, extension 1767; fax: +1 4187241842 . E-mail address: huixiang_xie@uqar.ca (H. Xie).

Recent evidence has demonstrated that carbon monoxide $(\mathrm{CO})$ is enriched in the bottom layer of first-year Arctic sea ice during ice algal blooms, but the processes responsible for this enrichment are not well understood. This study presents spectral apparent quantum yields (AQYs) of $\mathrm{CO}$ photoproduction from chromophoric dissolved organic matter $(\mathrm{CDOM})$ and particulate organic matter $(\mathrm{POM})$ harvested from three monocultures of ice algae (P. taeniata, A. septentrionalis, and $N$. frigida) and a natural ice algal assemblage collected from Resolute Bay, Canada. The AQYs for both $\mathrm{CDOM}$ and POM declined with increasing wavelength. Prolific CO photoproduction was observed from POM at wavelength $(\lambda)>600 \mathrm{~nm}$, while little $\mathrm{CO}$ was photochemically produced from $\mathrm{CDOM}$ at $\lambda>500 \mathrm{~nm}$. Although POM-based CO AQY spectra exhibit considerable dependence on ice algal species and growth stage, POM collected from all cultures and from both the exponential and senescent phases were far more efficient at CO photoproduction than the corresponding CDOM, particularly at visible wavelengths. AQY-based modeling suggests that POM 
dominates over $\mathrm{CDOM}$ in controlling $\mathrm{CO}$ photoproduction in bottom sea ice during ice algal blooms due to a combination of much higher photoreactivity of POM relative to $\mathrm{CDOM}$ at visible wavelengths, higher transmission of visible radiation in sea ice, and higher ratios of particle to CDOM absorption.

Key words: ice algae; CDOM and POM; photochemistry; carbon monoxide 3 34

\section{Introduction}

Sea ice plays an important role in carbon cycling in polar oceans via biological production by ice algae. Ice algae can provide $3-25 \%$ of the total primary production in seasonally ice covered Arctic seas and $>50 \%$ in the central Arctic Ocean (Gosselin et al., 1997). Dissolved organic carbon (DOC) production by ice algae accounts for about $40 \%$ of the total organic carbon fixation in sea ice (Gosselin et al., 1997; Smith et al., 1997). During ice algal blooms, dissolved organic matter (DOM) in bottom sea ice is highly enriched relative to the underlying seawater; the abundance of sea-ice DOM, as indicated by the concentration of DOC and the absorbance of chromophoric DOM (CDOM), is correlated with the ice algal standing stock or the concentration of particulate organic carbon (POC) (Smith et al., 1997; Riedel et al., 2008; Song et al., 2011; Xie et al., 2014).

Notably, biological activity of sea ice communities and/or the associated cycling of DOM are sources of certain atmospherically and/or climatically reactive trace gases, such as dimethylsulfide (Levasseur et al., 1994; Levasseur, 2013; Turner et al., 1995), nitrous oxide (Randall et al., 2012; Lovely et al., 2015), and carbon monoxide (CO) (Xie and Gosselin, 2005; Song et al., 2011). During ice algal blooms, large amounts 
of CO can accumulate in the lowermost layer of sea ice where ice algae thrive (Xie and Gosselin, 2005; Song et al., 2011). As sea ice is permeable at temperatures above $-15^{\circ} \mathrm{C}$ (Gosink et al., 1976), it has been posited to be a potentially significant source of atmospheric CO (Song et al., 2011). CO regulates the oxidizing capacity of the atmosphere (Thompson, 1992) and acts as an indirect greenhouse gas (Zepp et al., 2011) through its reaction with the hydroxyl radical. Brine drainage and ice melting also bring $\mathrm{CO}$ down to the water column where it is consumed by CO-oxidizing bacteria (Moran and Miller, 2007; Xie et al., 2009a) and/or emits to the atmosphere.

Seasonal variations in $\mathrm{CO}$ concentration $([\mathrm{CO}])$ in the bottom layer of Arctic firstyear sea ice generally parallels those in chlorophyll $a$ concentration ([Chl $a])$ and CDOM absorption coefficient ( $\left.a_{\mathrm{CDOM}}\right)$ (Xie and Gosselin, 2005; Song et al., 2011; Xie et al., 2014). Given that photooxidation of CDOM is the main CO production pathway in open seawater (Conrad and Seiler, 1980; Zafiriou et al., 2003), the correlation between $[\mathrm{CO}]$ and $a_{\mathrm{CDOM}}$ in sea ice suggests that CDOM photodegradation could be an important contributor to $\mathrm{CO}$ accumulation in sea ice during ice algal blooms. This supposition is supported by the study of Xie and Gosselin (2005) demonstrating that irradiation of sea ice refrozen from Arctic sea ice meltwater can produce considerable amounts of $\mathrm{CO}$. More recently, particulate organic matter (POM) photodegradation has been identified to be an important source of $\mathrm{CO}$ in open seas (Xie and Zafiriou, 2009; Song et al., 2013, 2015). Considering the correspondence between $[\mathrm{CO}]$ and $[\mathrm{Chl} a]$ in sea ice, the enormous ice algal biomass during the vernal bloom, and the ability of algal pigments to absorb photosynthetically available radiation (PAR, 400-700 $\mathrm{nm}$ ), we hypothesize that POM photochemistry can be the dominant source of $\mathrm{CO}$ in sea ice during ice algal blooms. Here we determined and compared the apparent quantum yield (AQY) spectra of CO photoproduction $\left(\Phi_{\lambda}\right)$ 
from particles and CDOM collected from laboratory ice algal cultures. Furthermore, the relative contributions of $\mathrm{CDOM}$ and particles to total $\mathrm{CO}$ photoproduction in bottom sea ice during ice algal blooms were estimated based on the obtained $\Phi_{\lambda}$ and absorption spectra of particles and CDOM. Results from this study help better understand the importance of photochemistry in carbon and trace gas cycling in sea ice.

\section{Methods}

\subsection{Culture incubations}

Eighty milliliters of non-axenic monocultures of P. taeniata, A. septentrionalis, $N$. frigida and a natural ice algal assemblage (NIAA) collected from bottom sea ice in Resolute Bay (Table 1) were inoculated into $0.8 \mathrm{~L}$ sterilized f/2 medium contained in 1 L Erlenmeyer flasks. The f/2 medium, containing vitamins and silica, was prepared according to the recipe of Natural Center for Marine Algae and Microbiota (NCMA) at Bigelow Laboratory. The stock solutions of the chemicals for preparing the $f / 2$ medium were purchased from NCMA and added to $0.2-\mu \mathrm{m}$ filtered deep seawater collected from Canada Basin. The selected species are dominant diatoms in sea ice on the shelves of Chukchi Sea and Beaufort Sea (von Quillfeldt et al., 2003; Poulin et al., 2011). The NIAA was chosen to investigate potential differences in photoreactivities of CDOM and POM produced by monocultures and natural algal assemblages. All cultures were incubated in duplicate at $4^{\circ} \mathrm{C}$ under illumination of cool white fluorescent light. Light intensities and durations of light:dark cycles are shown in Table 1. A parallel medium-only control served to assess any potential alterations of the organic matter photoreactivity in the medium. The temporal progression of [Chl $a$ ] was monitored to examine the growth stages of the cultures. Biomass in terms of [Chl 
a] in duplicate flasks for each culture agreed within $10 \%$ throughout the incubation periods.

\subsection{Sample collection}

A schematic description of sample collection and processing is shown in Fig. A1 in Appendix A. Briefly, at about the middle of the exponential phase (EP) in each culture (see sampling dates in Fig. A2 in Appendix A), $~ 10 \mathrm{~mL}$ of culture was collected from one of the duplicate cultures and the particulate matter in the culture was filtered onto a combusted Whatman GF/F filter (pore size: $0.7-\mu \mathrm{m}$; diameter: $25 \mathrm{~mm}$ ) for determining the absorption spectra of particles. Moreover, $\sim 600 \mathrm{~mL}$ of the above culture was gravity-filtered through a clean $10-\mu \mathrm{m}$ Nitex screen to separate the ice algal cells from the liquid phase and bacteria. The filtrate as well as the culture's medium control, was sequentially filtered through GF/F (diameter: $47 \mathrm{~mm}$ ) and 0.2$\mu \mathrm{m}$ polyethersulfone (PES) filters under low vacuum $(<50 \mathrm{kPa})$. The remaining culture $(\sim 100 \mathrm{~mL})$ was left in the flask for further incubation in order to compare its $[$ Chl $a$ ] with that in the other duplicate culture which was sampled during the senescent phase (SP) in the same manner as that for the exponential phase. The final filtrate was stored $\operatorname{cool}\left(4^{\circ} \mathrm{C}\right)$ in the dark before being analyzed for CDOM absorption spectra and CO AQYs. The particles (i.e. algal cells plus detritus) retained on the

Nitex screen were gently rinsed several times with artificial seawater (ASW) until the absorption coefficient of CDOM at $330 \mathrm{~nm}\left(a_{\mathrm{CDOM}, 330}\right)$ in the rinsing solution reached $<0.03 \mathrm{~m}^{-1}$. The rinsing was purported to diminish bacteria and DOM retained on the ice algal cells, thereby minimizing potential microbial CO consumption and DOMbased $\mathrm{CO}$ photoproduction during irradiation of the particle-containing samples (see below). 
The ASW was prepared according to the protocol of Berges et al. (2001) and composed of $\mathrm{Na}^{+}, \mathrm{K}^{+}, \mathrm{Ca}^{2+}, \mathrm{Mg}^{2+}, \mathrm{SO}_{4}{ }^{2-}$ and $\mathrm{Cl}^{-}$with a salinity $\sim 34 . \mathrm{NaCl}, \mathrm{KCl}$, and $\mathrm{Na}_{2} \mathrm{SO}_{4}$ were combusted at $400^{\circ} \mathrm{C}$ for ca. $4 \mathrm{~h}$ to remove any organic impurities. Before use, the ASW was vacuum-filtered with 0.2- $\mu \mathrm{m}$ PES filters and then irradiated for $24 \mathrm{~h}$ under solar-simulated radiation emitted from an XLS+ solar simulator to further reduce the ASW's DOM content (final [DOC]: $12 \mu \mathrm{mol} \mathrm{L}^{-1}, a_{\mathrm{CDOM}, 330}: 0.004$ $\left.\mathrm{m}^{-1}\right)$

\subsection{Irradiation}

After flushing with the ASW, the particles retained on the mesh were immediately dispersed into $2.5 \mathrm{~L} \mathrm{ASW}$ (herein referred to as particle sample or particlecontaining sample), gently stirred with a Teflon-skinned magnetic bar and bubbled with CO-free air to minimize the background [CO]. After $\sim 30$ min bubbling, part of the water was transferred into $44 \mathrm{~mL}$ quartz-windowed cells (ID: $24 \mathrm{~mm}$, length: 140 $\mathrm{mm})$; the cells were closed without headspace after sample filling. Eight sample-filled cells were vertically placed in a temperature-controlled $\left(4^{\circ} \mathrm{C}\right)$ water bath and irradiated with a CPS solar simulator under full spectrum to determine CO photoproduction as a function of irradiation time. Two cells were sacrificed at a time for $[\mathrm{CO}]$ determination. The wavelength-dependence of $\mathrm{CO}$ photoproduction was assessed with successive Schott long-band cutoff filters of WG280, WG295, WG305, WG320, WG345, GG395, GG435, GG495 and OG570, where the numeric values signify the nominal $50 \%$ transmittance cutoff wavelengths $\left(\lambda_{50 \% \mathrm{~T}}\right)$ in nanometers. The sidewalls of the cells were wrapped with black electric tape to prevent lateral light interference between the cells. Irradiation lasted <40 min for the WG280, WG295, WG305 and WG320 cutoff filters, and $<1.5 \mathrm{~h}$ for the rest. The quartz cells were 
shaken gently before irradiation and every $30 \mathrm{~min}$ thereafter to minimize particle settlement.

The remaining part of the bubbled, unirradiated particle-containing water was filtered through pre-combusted GF/F filters under low vacuum $(<50 \mathrm{kPa})$ for determining the particle and CDOM absorption spectra and [DOC]. The filtrate was irradiated in the same manner as above to determine the wavelength-dependent $\mathrm{CO}$ photoproduction from residual CDOM remaining in the ASW plus that potentially released from particles during bubbling. All irradiations were accompanied with parallel dark controls.

After irradiation, [CO] was determined using the headspace method reported by Xie et al. (2002). Briefly, samples were transferred to a 50-mL glass syringe, into which $5 \mathrm{~mL}$ CO-free air was introduced to obtain a 1:6 gas:water ratio. The syringe was shaken for 3 min using a Burrell Wrist-Action Shaker (model: DD) and the equilibrated headspace gas was injected into a Trace Analytical Reduction Gas Analyzer (model: TA3000) for CO quantification. The analyzer was calibrated by frequent injections of a National Institute of Standards and Technology (NIST)traceable gaseous $\mathrm{CO}$ standard of 1.23 parts per million by volume (Praxair). The uncertainty of $\mathrm{CO}$ measurement was within $\pm 2 \%$ and the detection limit was 0.02 nmol $\mathrm{L}^{-1}$. The particle-containing samples left after $[\mathrm{CO}]$ determination were filtered under low vacuum $(<50 \mathrm{kPa}$ ) through $25-\mathrm{mm}$ pre-combusted $\mathrm{GF} / \mathrm{F}$ (Whatman) filters for determining the absorption spectra of particles and CDOM and [DOC]. It was found that these quantities did not change significantly $(<6 \%)$ during irradiation and $[\mathrm{CO}]$ analysis. The absorption spectra of particles and CDOM used for retrieving CO AQY (see section 2.5) were the averages of before- and after-irradiation. Note that the dissolved and particulate phases here were demarcated by the GF/F (i.e. $0.7-\mu \mathrm{m}$ pore 
size) filtration, as required by the use of $\mathrm{GF} / \mathrm{F}$ filters to retain particles for particulate absorbance measurement. To distinguish the GF/F filtration-based CDOM absorption coefficients from those based on the $0.2-\mu \mathrm{m}$ filtration (see section 2.2.), the former is designated as $a_{\text {CDOM }}^{\prime}$ herein. However, no significant difference in CDOM absorbance ( $<4 \%)$ was observed between the two-filtration procedures (GF/F vs. $0.2-\mu \mathrm{m}$ PES).

The $0.2-\mu \mathrm{m}$ filtrates from the medium control and the algal cultures were bubbled and irradiated in the same manner as described above to determine the AQY spectra of CO photoproduction from CDOM. The OG570 cutoff filter was not used for the CDOM-only samples, given no $\mathrm{CO}$ photoproduction observed at wavelength $>600$ nm (Xie et al., 2009b; Song et al., 2013).

\subsection{Sample analyses}

Chlorophyll $a$ was extracted in $10 \mathrm{~mL}$ of $90 \%$ acetone in scintillation vials for at least $18 \mathrm{~h}$ in darkness at $\sim 4^{\circ} \mathrm{C}$. The supernatant was measured for fluorescence, before and after being acidified with $5 \% \mathrm{HCl}$, using a Turner Designs fluorometer (model 10-AU) according to the method of Parsons et al. (1984). [Chl $a$ ] was calculated using the equation of Holm-Hansen et al. (1965).

The optical density $(O D)$ of particles retained on the filters was measured using a Perkin Elmer Lambda 850 dual beam spectrometer fitted with a 150-mm integrating sphere accommodating a filter holder (Röttgers and Gehnke, 2012). The spectral optical density of the filter, $O D_{\mathrm{f}, \lambda}$, where $\lambda$ is wavelength in nanometers, was recorded from $800 \mathrm{~nm}$ to $290 \mathrm{~nm}$ at $1-\mathrm{nm}$ increments and a scanning speed of $120 \mathrm{~nm} \mathrm{~min}^{-1}$. $O D_{\mathrm{f}, \lambda}$ was converted to the spectral particulate absorption coefficient, $a_{\mathrm{p}, \lambda}\left(\mathrm{m}^{-1}\right)$, using Eq. 1, 


$$
a_{p, \lambda}=2.303 \times(A / V) \times\left(O D_{f, \lambda}-O D_{\text {blank }, \lambda}\right) \times\left(1 / \beta_{\lambda}\right)
$$

where $O D_{\text {blank }, \lambda}$ is the optical density of a blank filter, $A$ the clearance area of particles on the filter $\left(\mathrm{m}^{2}\right), V$ the volume of sample water filtered $\left(\mathrm{m}^{3}\right)$, and $\beta_{\lambda}$ the pathlength amplification factor. $\beta_{\lambda}$ was nonlinearly correlated with $O D_{\mathrm{f}, \lambda}$ (Röttgers and Gehnke, 2012):

$$
\beta_{\lambda}=2.9 \times O D_{f, \lambda}^{2}-4.76 \times O D_{f, \lambda}+4.5
$$

Upon the completion of $a_{\mathrm{p}, \lambda}$ determination, the filter was dipped in $10 \mathrm{~mL}$ methanol for $\sim 18 \mathrm{~h}$ to bleach pigments, leaving only the non-algal particles (i.e. detritus) on the filter. The absorption coefficient of the non-algal particles, $a_{\mathrm{nap}, \lambda}\left(\mathrm{m}^{-1}\right)$, was determined in the same manner as that for $a_{\mathrm{p}, \lambda}$. Subtracting $a_{\mathrm{nap}, \lambda}$ from $a_{\mathrm{p}, \lambda}$ gave the phytoplankton absorption coefficient, $a_{\mathrm{phy}, \lambda}\left(\mathrm{m}^{-1}\right)$.

The beam attenuation coefficient, $c\left(\mathrm{~m}^{-1}\right)$, of the particle-containing sample was determined after bubbling (section 2.3) using a Perkin-Elmer Lambda 35 dual beam spectrophotometer coupled with $10-\mathrm{cm}$ cylindrical quartz cells with the same diameter of the irradiation cells. The scattering coefficient, $b\left(\mathrm{~m}^{-1}\right)$, of particles at each wavelength is calculated by subtracting $a_{\mathrm{t}}$ from $c$ (i.e. $b=c-a_{\mathrm{t}}$ ). Here $a_{\mathrm{t}}$ is the total absorption coefficient of the sample, i.e. the sum of $a_{\mathrm{p}}, a_{\text {CDOM }}^{\prime}$ and the absorption coefficient of pure water $\left(a_{\mathrm{w}}\right)$ (Buiteveld et al., 1994; Pope and Fry, 1997).

The spectral optical density of CDOM, $O D_{\mathrm{CDOM}, \lambda}$, was scanned from $800 \mathrm{~nm}$ to $200 \mathrm{~nm}$ at 1-nm intervals with a Perkin Elmer Lambda 35 dual beam spectrometer fitted with a 5-cm flow-through quartz cuvette and referenced to MilliQ water. Samples were allowed to warm up to room temperature before analysis. The sample cuvette was rinsed with methanol, pure water, and sample water between individual scans. A baseline correction was applied by subtracting the optical density averaged over 683-687 nm from all $O D_{\mathrm{CDOM}, \lambda}$ values (Babin et al., 2003). The spectral CDOM 
absorption coefficient, $a_{\mathrm{CDOM}, \lambda}$ was calculated as 2.303 times $O D_{\mathrm{CDOM}, \lambda}$ divided by the light pathlength of the cell in meters $(0.05 \mathrm{~m})$.

For [DOC] determination, $8 \mathrm{~mL}$ sample was transferred into a $9 \mathrm{~mL}$ clean glass vial, added with $100 \mu \mathrm{L} 2 \mathrm{~N} \mathrm{HCl}$, and stored in the refrigerator until analysis. [DOC] was analyzed in triplicate using a Shimadzu TOC-5000A Total Carbon Analyzer calibrated with potassium biphthalate. The system was checked, every seven consecutive sample analyses, against Hansell's low-carbon ([DOC]: 1-2 $\mu \mathrm{mol} \mathrm{L} \mathrm{L}^{-1}$ ) and deep Sargasso Sea ([DOC]: $44-46 \mu \mathrm{mol} \mathrm{L^{-1 }}$ ) reference waters. The mean coefficient of variation of triplicate measurements was $1.3 \%(0.1 \%-13.5 \%)$.

\subsection{Retrieval of CO AQY spectra}

The amount of $\mathrm{CO}$ photochemically produced was calculated as the difference between an irradiated sample and its parallel dark control. The spectral CO AQY, $\Phi_{\lambda}$, is defined as the number of moles of CO produced per mole of photons absorbed by a given set of light-absorbing materials at wavelength $\lambda$. Here the light-absorbing materials refer to $\mathrm{CDOM}$ or particles, corresponding to $\Phi_{\lambda}$ for $\mathrm{CDOM}\left(\Phi_{\mathrm{CDOM}, \lambda}\right)$ or particles $\left(\Phi_{\mathrm{p}, \lambda}\right)$, respectively. According to $\mathrm{Hu}$ et al. (2002), the number of photons absorbed by CDOM or particles at wavelength $\lambda, Q_{\mathrm{a}, \lambda}$ (mol photons s${ }^{-1} \mathrm{~nm}^{-1}$ ), can be calculated as follows:

$$
Q_{a, \lambda}=Q_{\lambda} \times S \times\left(a_{\lambda} / a_{t, \lambda}\right) \times\left[1-\exp \left(-a_{t, \lambda} \times L\right)\right]
$$

$Q_{\lambda}$ (mol photons $\mathrm{m}^{-2} \mathrm{~s}^{-1} \mathrm{~nm}^{-1}$ ) denotes the photon flux just below the frontal quartz window of the irradiation cell; $a_{\lambda}\left(\mathrm{m}^{-1}\right)$ stands for $a_{\mathrm{CDOM}, \lambda}$ for the $0.2-\mu \mathrm{m}$ filtered samples or $a_{\mathrm{p}, \lambda}$ for the particle-containing samples; $a_{\mathrm{t}, \lambda}\left(\mathrm{m}^{-1}\right)$ is the total absorption coefficient, i.e. $a_{\mathrm{CDOM}, \lambda}$ plus $a_{\mathrm{w}, \lambda}$ (Buiteveld et al., 1994; Pope and Fry, 1997) for the $0.2-\mu \mathrm{m}$ filtered samples, or the sum of $a_{\mathrm{p}, \lambda}, a_{\mathrm{CDOM}, \lambda}^{\prime}$, and $a_{\mathrm{w}, \lambda}$ for the particle- 
251 containing samples. $S\left(\mathrm{~m}^{2}\right)$ and $L(\mathrm{~m})$ are, respectively, the cross section and the 252 pathlength of the irradiation cell. Particles can scatter photons out of the irradiation 253 cell and change the effective pathlength of light transmission (Miller and Zepp, 1979; 254 Estapa et al., 2012). Following the procedure published by Song et al. (2013), we 255 estimated the contribution of particle scattering to light attenuation in the particle256 containing samples using Monte Carlo simulations run by the SimulO software 257 (Leymarie et al., 2010). The particle scattering effect decreased with increasing 258 wavelength for samples collected from both the exponential and senescent phases but 259 a shoulder over $450-670 \mathrm{~nm}$ was evident for the exponential-phase samples (Fig. A3 in Appendix A).

CDOM- and particle-based CO AQY spectra were retrieved using the iterative fitting method reported previously (e.g. Xie et al., 2009b; Song et al., 2013), and the forms of Eqs. 4 (quasi-exponential) and 5 (simple exponential) were employed for $\Phi_{\lambda}$ retrieval:

$$
\Phi_{\lambda}=m_{4} \times \exp \left(m_{5} \times(\lambda-290)\right)
$$

where $m_{1}-m_{5}$ are fitting parameters. The amount of $\mathrm{CO}$ produced in an irradiation cell over the exposure time could then be predicted as the product of the assumed $\Phi_{\lambda}$ 269 function and the number of absorbed photons integrated over 290-600 $\mathrm{nm}$ for CDOM 270 and over $290-700 \mathrm{~nm}$ for particles. The optimum values of $m_{1}-m_{5}$ were identified by 271 varying their initial estimates until the difference between the predicted $\mathrm{CO}$ 272 production rate and the measured one for an entire set of irradiation reached a 273 minimum. Tests indicated that Eq. 4 worked much better than Eq. 5 for particles, 274 while vice versa for CDOM, based on $R^{2}$ for the regression of CO production rates 275 calculated from the retrieved $\Phi_{\lambda}$ against the measured rates and the normalized root- 
mean-squared errors (Koehler et al., 2016) (Table A2 in Appendix A). Therefore, Eqs. 4 and 5 were chosen for particles and CDOM, respectively.

Notably, the parallel control experiments showed CO photoproduction from the residual CDOM in the ASW and the CDOM potentially released from particles during bubbling (see section 2.3 ) was $3.1 \% \pm 2 \%(0.4 \%-7.5 \%)$ of the total $\mathrm{CO}$ photoproduction (particles plus CDOM) under each cutoff filter for all cultures; the CO photoproduction rate from particles was corrected for this artifact and for any thermal $\mathrm{CO}$ production occurring in the dark controls, which ranged from $<2 \%$ of the CO photoproduction under the WG280 cutoff filter to $<15 \%$ under the OG 570 cutoff filter.

To facilitate comparison of various $\Phi_{\lambda}$ spectra, a solar irradiance spectrumweighted mean apparent quantum yield, $\bar{\Phi}$, was computed for each individual CO AQY spectrum following the procedure of Zhang et al. (2006):

$$
\bar{\Phi}=\left(\int_{290}^{600} Q_{0, \lambda} \times \Phi_{\lambda} \times d \lambda\right) /\left(\int_{290}^{600} Q_{0, \lambda} \times d \lambda\right)
$$

$\bar{\Phi}$ denotes $\bar{\Phi}_{\mathrm{CDOM}}$ for CDOM and $\bar{\Phi}_{\mathrm{p}}$ for particles, respectively. $Q_{0, \lambda}$ (mol photons $\mathrm{m}^{-2}$ $\mathrm{h}^{-1} \mathrm{~nm}^{-1}$ ) is the surface spectral solar photon fluxes at $70^{\circ} \mathrm{N}, 133^{\circ} \mathrm{W}$ at $14: 00$ local time on 01 July, simulated using the SMARTS model (Simple Model of the Atmospheric Radiative Transfer of Sunshine; Gueymard, 2001) under mid-summer Arctic atmospheric and cloudless conditions with an ozone column burden of 330 Dobson Units. This normalization reduces the full AQY spectrum to a single value corresponding to the amount of $\mathrm{CO}$ produced in an idealized water column divided by the amount of photons absorbed by CDOM or particles; in this water column, CDOM or particles are the sole light absorber. Although $\Phi_{\mathrm{p}, \lambda}$ was modeled in the wavelength range from $290 \mathrm{~nm}$ to $700 \mathrm{~nm}, \bar{\Phi}_{p}$ was integrated from $290 \mathrm{~nm}$ to $600 \mathrm{~nm}$ to facilitate 
comparison with $\bar{\Phi}_{\mathrm{CDOM}}$ and with $\bar{\Phi}_{\mathrm{p}}$ published in a previous study (Song et al., 2013).

3. Results and discussion

For simplicity, symbols of absorption coefficients and CO AQYs are followed by EP and SP in parentheses, if needed, to distinguish the exponential and senescent phases, respectively, e.g. $a_{\mathrm{CDOM}, 330}(\mathrm{EP})$ and $\bar{\Phi}_{p}(\mathrm{EP})$ denoting $a_{\mathrm{CDOM}, 330}$ and $\bar{\Phi}_{p}$ obtained from the exponential phase. It is further stipulated that symbols of absorption coefficients and CO AQYs can be used herein as both a singular and a plural form. Units of CO AQYs (mol CO (mol photons) $)^{-1}$ ) are omitted.

\subsection{General chemical, biological and optical properties}

All cultures reached exponential growth, in 1-4 weeks after inoculations. The maximum [Chl $a$ ] was $714 \mu \mathrm{g} \mathrm{\textrm {L } ^ { - 1 }}$ for P. taeniata, $234 \mu \mathrm{g} \mathrm{\textrm {L } ^ { - 1 }}$ for A. septentrionalis,

$31374.8 \mu \mathrm{g} \mathrm{L}^{-1}$ for $N$. frigida, and $347 \mu \mathrm{g} \mathrm{\textrm {L } ^ { - 1 }}$ for NIAA. Incubations lasted sufficiently long (94 to $166 \mathrm{~d}$, Table 1) to allow significant Chl $a$ decay to occur (Fig. A2 in Appendix A).

$[\mathrm{Chl} a] \mathrm{s}$ in the particle samples for irradiation experiments were $\sim 3-4$ times lower than their corresponding concentrations in the cultures due to dilution $(\sim 1: 3)$ and potential pigment losses during the cell rising with ASW. [Chl $a] \mathrm{s}$ in the EP particle samples were 3 to 8 times higher than those in the SP samples (Table 2). Likewise, the particle absorption coefficients at $443 \mathrm{~nm}\left(a_{\mathrm{p}, 443}\right)$ for the EP samples were also higher than their SP counterparts. The $a_{\mathrm{p}}(\mathrm{EP})$ spectra displayed a clear pigment peak at $\sim 676$ $\mathrm{nm}$ and a shoulder spanning from $380 \mathrm{~nm}$ to $500 \mathrm{~nm}$ and centered at $\sim 443 \mathrm{~nm}$. During the SP, the decay of algal cells diminished (Fig. 1A) or nearly eliminated (Fig. 1B) the characteristic pigment absorption peak and shoulder, thereby leading to a smaller 
$a_{\mathrm{phy}, 443}: a_{\mathrm{p}, 443}$ ratio relative to that for the EP (Table 2 ).

Both [DOC] and $a_{\mathrm{CDOM}, 330}$ in the cultures were higher than those in the medium control (Table 2), indicative of production of DOC and CDOM by the ice algae. The net accumulations of DOC and $a_{\mathrm{CDOM}, 330}$ were $39.2-253.4 \mu \mathrm{mol} \mathrm{L}-1$ and $0.22-1.57 \mathrm{~m}^{-1}$

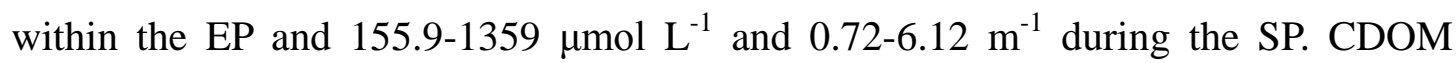
absorption coefficients in three of the four cultures were higher than those in the medium control throughout the wavelength range from $300 \mathrm{~nm}$ to $600 \mathrm{~nm}$, as exemplified by NIAA (Fig. 1D). CDOM absorption coefficients for the exponential growth phase of $P$. taeniata were nonetheless lower than those in the medium control at $\lambda \geq 375 \mathrm{~nm}$ (Fig. 1C) due probably to bacterial DOM consumption surpassing algal DOM production during the relatively early stage of the algal growth.

\subsection{Confirmation of $\mathrm{CO}$ photoproduction from particles}

Compared with the dark controls, $a_{\mathrm{p}}$ did not significantly decrease after irradiation under all light filters while $[\mathrm{DOC}]$ and $a_{\mathrm{CDOM}}^{\prime}$ did not substantially increase (Table A3 in Appendix A). Hence, $\mathrm{CO}$ should be produced primarily from particles not from POM-derived DOM, consistent with the results of Song et al. (2013). In addition, [DOC] and $a_{\mathrm{CDOM}}$ did not change significantly in the particle-free $(0.2-\mu \mathrm{m}$ filtered) samples before and after irradiation $(<3 \%)$. A time-course test demonstrated that $[\mathrm{CO}]$ in the particle samples increased linearly over $1.5 \mathrm{~h}$ (the longest exposure for CO AQY determinations) of full-spectrum irradiation (Fig. 2A). $[\mathrm{CO}]$ in the parallel dark controls either increased linearly (P. taeniata and NIAA) or remained nearly constant (A. septentrionalis and N. frigida) with time (Fig. 2B), confirming that the filtration and flushing procedure (see section 2.2) essentially eliminated microbes, at least the $\mathrm{CO}$-oxidizing bacteria. The increase in $[\mathrm{CO}]$ in the 
cultures of $P$. taeniata and NIAA could be attributed to thermal and/or biological production of $\mathrm{CO}$ from particles. However, the dark $\mathrm{CO}$ production rates were only < $2 \%$ and $<1 \%$ of the rates in the light treatments of $P$. taeniata and NIAA, respectively. CO photoproduction rates for both particles and CDOM decreased with increasing $\lambda_{50 \% \mathrm{~T}}$ of the cutoff filters (Fig. 3). However, the production rate for particles decreased more slowly than that for CDOM. Under filter GG495 $\left(\lambda_{50 \% \mathrm{~T}}: 495 \mathrm{~nm}\right)$, the particlebased $\mathrm{CO}$ production rate was 5-130 times the CDOM-based rate for the EP and 1.27.3 times for the SP. Moreover, significant $\mathrm{CO}$ formation from particles occurred under filter OG570 $\left(\lambda_{50 \% \mathrm{~T}}: 570 \mathrm{~nm}\right)$. Gros et al. (2009) reported that CO could be produced by phytoplankton via biological processes. To test if there was significant biological $\mathrm{CO}$ production by ice algae during irradiation, a $N$. frigida-containing particle sample was poisoned with potassium cyanide (final concentration: $4.2 \mu \mathrm{mol}$

$\mathrm{L}^{-1}$ ) and irradiated under conditions identical to those for the parallel unpoisoned sample. CO production rates in the poisoned sample were $<7 \%$ lower than in the unpoisoned sample under filters GG495 and OG570 and <4\% under the other light filters. Given that cyanide with a concentration of $4.2 \mu \mathrm{mol} \mathrm{\textrm {L } ^ { - 1 }}$ inhibits $\mathrm{CO}$ photoproduction by a similar range (Song et al., 2013), the $<7 \%$ difference could be ascribed to the cyanide inhibitory effect instead of biological CO production. Hence, $\mathrm{CO}$ production in the particle samples predominantly originated from particle photochemistry within the short irradiation durations $(\leq 1.5 \mathrm{~h})$ adopted in the present study.

\subsection{CO AQY spectra and $\bar{\Phi}$}

Notably, CDOM in each culture was composed of two pools: the algal-derived CDOM and CDOM originally contained in the $\mathrm{f} / 2$ medium. The CO AQY of CDOM 
determined in this study represents the mixture of these two CDOM pools, designated as total CDOM herein. The CO AQY of the algal-derived CDOM $\left(\Phi_{\mathrm{CDOM}, \mathrm{alg}, \lambda}\right)$ can be expressed as follows (see Eqs. A1-A8 in Appendix A for the detailed procedure of derivation):

$\Phi_{\mathrm{CDOM}, \mathrm{alga}, \lambda}=$

$\Phi_{\mathrm{CDOM}, \mathrm{t}, \lambda}+\left(\Phi_{\mathrm{CDOM}, \mathrm{t}, \lambda}-\Phi_{\mathrm{CDOM}, \text { medium }, \lambda}\right) \times\left(a_{\mathrm{CDOM}, \text { medium }, \lambda} / a_{\mathrm{CDOM}, \mathrm{alga}, \lambda}\right)$

where $\Phi_{\mathrm{CDOM}, \mathrm{t}, \lambda}$ and $\Phi_{\mathrm{CDOM}, \text { medium }, \lambda}$ denote $\mathrm{CO}$ AQYs for the total CDOM and the medium-based CDOM, respectively, and $a_{\mathrm{CDOM}, \text { alga, } \lambda}$ and $a_{\mathrm{CDOM}, \text { medium, }, \lambda}$ are absorption coefficients of the algal-derived CDOM and the medium-based CDOM, respectively. $\Phi_{\mathrm{CDOM}, \mathrm{t}, \lambda}$ was determined with the culture filtrates, and $\Phi_{\mathrm{CDOM}, \mathrm{medium}, \lambda}$ with the medium control, assuming that $\mathrm{CO}$ AQY for the medium-based CDOM in the cultures was comparable to that in the medium control. The ratio of $a_{\mathrm{CDOM}, \text { medium, } \lambda}$ to $a_{\mathrm{CDOM}, \mathrm{alga}, \lambda}$ in the culture filtrates is unknown, because $a_{\mathrm{CDOM}, \text { medium, }, \lambda}$ for the medium control, which was determined experimentally, may not be equated to $a_{\mathrm{CDOM}, \text { medium, },}$ in the cultures due to very likely faster consumption and degradation of the mediumbased CDOM in the cultures linked to the presence of algae and larger populations of bacteria as compared to the medium control. Besides, in separate incubations using the same ice algal species to investigate algal CDOM production, we found similar losses of CDOM absorbance in the $\mathrm{f} / 2$ medium control and the cultures during the first 2-d incubations (G. Li et al., unpublished data), which might also occur in the present study. We suspect that this early loss of CDOM was due to photobleaching of very reactive CDOM constituents contained in the $f / 2$ medium under cool white fluorescent illumination used for culture incubations. However, since the CDOM losses associated with photobleaching in the medium control and the cultures were similar, they should not affect the CDOM abundance in the cultures relative to that in 
400

401

402

403

404

405

406

407

408

409

410

411

412

413

415

416

417

418

419

420

421

422

423

424

the medium control.

Although the lack of knowledge of the $a_{\mathrm{CDOM}, \text { medium, }, \lambda} / a_{\mathrm{CDOM}, \text { alga, } \lambda}$ ratio in Eq. 7 makes it impossible to precisely determine $\Phi_{\mathrm{CDOM}, \text { alga, },}$, the lower and upper limits of $\Phi_{\mathrm{CDOM}, \text { alga }, \lambda}$ can be estimated under appropriate assumptions. Given that $\Phi_{\mathrm{CDOM}, \mathrm{t}, \lambda}$ was greater than $\Phi_{\mathrm{CDOM}, \text { medium, }, \lambda}$ (see below), the lower limit can be obtained by assuming the total $\mathrm{CDOM}$ in the culture filtrates to be entirely algal-derived (i.e. $a_{\mathrm{CDOM}, \text { medium, },}=$ 0 in Eq. 7), while the upper limit corresponds to the condition where the loss of the medium-based CDOM in the cultures equaled to that in the medium control, rendering $a_{\mathrm{CDOM}, \text { medium, }, \lambda}$ in the cultures to be identical to $a_{\mathrm{CDOM}, \text { medium, }, \lambda}$ in the medium control at the end of incubations. In terms of $\bar{\Phi}_{C D O M}$, the upper limit was 1.5 to 1.8 times the lower limit for the exponential phase and 1.2 to 1.5 times for the senescent phase, depending on species. In the discussion herein, $\Phi_{\mathrm{CDOM}}$ refers to the lower limit unless otherwise specified.

The fitted parameters for $\Phi_{\mathrm{p}, \lambda}$ and $\Phi_{\mathrm{CDOM}, \lambda}$ in Eqs. 4 and 5 , along with $\bar{\Phi}$, are shown in Table 3. $\Phi_{\mathrm{p}}$ was higher than its corresponding $\Phi_{\mathrm{CDOM}}$ for each culture and the difference increased with wavelength and up to several orders in the band of 500$600 \mathrm{~nm}$ (Fig. 4), which was consistent with the higher particle-based CO photoproduction rates at the visible wavelengths (Fig. 3). The $\Phi_{\mathrm{p}}(\mathrm{EP})$ and $\Phi_{\mathrm{p}}(\mathrm{SP})$ spectra were similar in both shape and magnitude for A. septentrionalis and NIAA, while the EP spectrum for P. taeniata sat well above the SP spectrum and became flatter than the latter at $\lambda>350 \mathrm{~nm}$ (Fig. 4A,B,D). The $\Phi_{\mathrm{CDOM}}$ spectra for P. taeniata showed no substantial difference between the two growth phases (Fig. 4A), whereas the $\Phi_{\mathrm{CDOM}}(\mathrm{EP})$ spectra for $A$. septentrionalis and NIAA gradually diverged from the corresponding SP spectra towards longer wavelengths (Fig 4B,D). The $\Phi_{\mathrm{CDOM}}(\mathrm{EP})$ spectra for $N$. frigida was above its corresponding SP spectra at shorter wavelengths 
but converged at longer wavelengths (Fig. $4 \mathrm{C}) . \Phi_{\mathrm{CDOM}}$ of the cultures was far higher than that of the medium control across the spectral range covered, particularly at longer wavelengths (Fig. 4), suggesting that CDOM produced by ice algae was more photoreactive than that contained in the medium in terms of CO photoproduction.

$\bar{\Phi}_{p}(\mathrm{EP})$ was higher than $\bar{\Phi}_{p}(\mathrm{SP})$ for $P$. taeniata, while the sequence was reversed for A. septentrionalis and NIAA, especially for the latter, with its $\bar{\Phi}_{p}(\mathrm{SP}) \sim 3$ times $\bar{\Phi}_{p}(\mathrm{EP})$ (Table. 3). These patterns remain the same even if the integration wavelength range is changed from $290-600 \mathrm{~nm}$ to $290-700 \mathrm{~nm}$ (data not shown). $\bar{\Phi}_{p}(\mathrm{EP})$ in descending order was: $P$. taeniata $\left(10.6 \times 10^{-6}\right)>$ NIAA $\left(6.74 \times 10^{-6}\right)>A$. septentrionalis $\left(3.40 \times 10^{-6}\right)>N$. frigida $\left(2.83 \times 10^{-6}\right)$, while $\bar{\Phi}_{p}(\mathrm{SP})$ in descending order was: NIAA $\left(18.2 \times 10^{-6}\right)>$ P. taeniata $\left(5.75 \times 10^{-6}\right) \approx$ A. septentrionalis $\left(5.51 \times 10^{-6}\right)$. The between-culture difference reached up to a factor of 3.7 for $\bar{\Phi}_{p}(\mathrm{EP})$ and 3.3 for $\bar{\Phi}_{p}(\mathrm{SP})$. Note that $\bar{\Phi}_{p}$ for the natural assemblage was the second highest for the EP and the highest for the SP. $\bar{\Phi}_{C D O M}$ for the cultures exhibited little phase-dependence, except $N$. frigida whose $\bar{\Phi}_{C D O M}(\mathrm{EP})$ was approximately twice $\bar{\Phi}_{C D O M}(\mathrm{SP})$ (Table 3). Comparisons among different cultures revealed that NIAA had the highest $\bar{\Phi}_{C D O M}(\mathrm{EP})$ $\left(3.61 \times 10^{-6}\right)$ followed sequentially by $N$. frigida $\left(2.18 \times 10^{-6}\right)$, P. taeniata $\left(1.99 \times 10^{-6}\right)$ and A. septentrionalis $\left(1.79 \times 10^{-6}\right)$. NIAA also possessed the highest $\bar{\Phi}_{C D O M}(\mathrm{SP})$ $\left(2.91 \times 10^{-6}\right)$ followed sequentially by $A$. septentrionalis $\left(1.94 \times 10^{-6}\right), P$. taeniata $\left(1.88 \times 10^{-6}\right)$ and $N$. frigida $\left(1.18 \times 10^{-6}\right)$ (Table 3$)$.

$\bar{\Phi}_{p}$ was consistently higher than $\bar{\Phi}_{C D O M}$ for all cultures and both growth phases, with the mean $\bar{\Phi}_{p} \sim 3$ times $\bar{\Phi}_{C D O M}$ for the EP and $\sim 5$ times for the SP. Even compared with the upper limits of $\bar{\Phi}_{C D O M}$, the mean $\bar{\Phi}_{p}$ was still 1.5 and 3.5 times the mean $\bar{\Phi}_{C D O M}$ for the EP and SP, respectively. The higher $\bar{\Phi}_{p}$ relative to $\bar{\Phi}_{C D O M}$ demonstrated 
that algal particles were more efficient at $\mathrm{CO}$ photoproduction than the algae-derived CDOM, consistent with previous results showing that particles are more photoreactive than CDOM in Arctic offshore seawater (Song et al., 2013). It is worth pointing out that $\Phi_{\mathrm{CDOM}}$ and $\Phi_{\mathrm{p}}$ were determined in different matrices, i.e. $\mathrm{f} / 2$ medium for $\Phi_{\mathrm{CDOM}}$ and ASW for $\Phi_{\mathrm{p}}$ (see section 2.3). The f/2 medium contained high concentrations of nitrate $\left(880 \mu \mathrm{mol} \mathrm{L} \mathrm{L}^{-1}\right)$ and dissolved iron $\left(11.7 \mu \mathrm{mol} \mathrm{L}^{-1}\right)$ and normal seawater concentrations of carbonate/bicarbonate and bromide, while these compounds were absent or negligible in the ASW. Both photolysis of nitrate (Zafiriou, 1974; Zafiriou and True, 1979) and iron-mediated CDOM photochemistry (Gao and Zepp, 1998) can produce reactive oxygen species, notably hydroxyl radicals, whose reaction with $\mathrm{DOM}$ is known to produce significant amounts of $\mathrm{CO}$ in freshwater samples (Gao and Zepp, 1998; Stubbins et al., 2008). Although hydroxyl radicals could be largely scavenged by halide and carbonate ions (principally bromide ions) (Zafiriou et al., 1987 ) in the f/2 medium, it was likely that the highly elevated concentrations of nitrate and iron increased $\Phi_{\mathrm{CDOM}}$ to some extent. Hence, the difference between $\Phi_{\mathrm{p}}$ and $\Phi_{\mathrm{CDOM}}$ could be even larger if the dissimilarity in the composition of the two matrices is taken into account.

\subsection{Comparison with previous studies}

Song et al. (2013) reported the only available wavelength-resolved $\Phi_{\mathrm{p}}$ for water samples collected from the western Canadian Arctic, including the Mackenzie River estuary, the Mackenzie Shelf, and the Canada Basin. The Canada Basin was chosen for comparison due to the least riverine influence and hence the highest proportion of phytoplankton-derived POM among the three sampling areas (Doxaran et al., 2012; Song et al., 2013). The average $\Phi_{\mathrm{p}}$ spectra for surface water and the deep chlorophyll 
maximum (DCM) layer in the Canada Basin are shown in Fig. 5A, alongside the average $\Phi_{\mathrm{p}}(\mathrm{EP})$ and $\Phi_{\mathrm{p}}(\mathrm{SP})$ spectra from this study. Clearly, both $\Phi_{\mathrm{p}}(\mathrm{EP})$ and $\Phi_{\mathrm{p}}(\mathrm{SP})$ are much higher than those obtained from the Canada Basin throughout the wavelength range of interest but the divergence increases with wavelength. Consequently, $\bar{\Phi}_{\mathrm{p}}$ for the cultures exceed those for the Canada Basin by a factor of 1.4-12.4, depending on species and growth phases. The large discrepancy in $\Phi_{\mathrm{p}}$ between the cultures and the Canada Basin could arise from many factors but potential differences in POM properties of pelagic vs. sympagic organisms may have played a role. However, the difference between the cultures and field samples falls into the range of variations associated with phase- and species-dependences of the cultures, as described above in this section.

Our lab had previously determined the $\Phi_{\mathrm{CDOM}}$ spectrum for meltwater of a firstyear drifting sea ice sample taken on 26 April 2008 from the bottommost 10-cm section of an ice core extracted at a site $\left(70.59^{\circ} \mathrm{N}, 122.44^{\circ} \mathrm{W}\right.$; station $\mathrm{D} 43-1$ in Song et al., 2011) located in the Amundsen Gulf of the western Canadian Arctic. The sea ice sampling took place during the vernal ice algal bloom and [Chl a] in the bottom section reached $573.0 \mu \mathrm{g} \mathrm{L}^{-1}$ (Song et al., 2011). The procedure and experimental conditions for determining $\Phi_{\mathrm{CDOM}}$ for the sea ice meltwater were identical to those for determining $\Phi_{\mathrm{CDOM}}$ for the cultures, save that the meltwater was irradiated at $1^{\circ} \mathrm{C}, 3^{\circ} \mathrm{C}$ lower compared with this study (see section 2.3). $\Phi_{\mathrm{CDOM}}$ averaged on the lower limits of all cultures and both growth phases is considerably lower, at $\lambda>350 \mathrm{~nm}$, than that of the sea ice meltwater but again the difference widens with wavelength (Fig. 5B). The lower- and upper-limit average $\bar{\Phi}_{\mathrm{CDOM}}(\mathrm{SP})$ for the cultures are $42 \%$ and $25 \%$ lower than that for the meltwater, respectively. Additionally, the lower-limit average $\bar{\Phi}_{\mathrm{CDOM}}(\mathrm{EP})$ for the cultures is $30 \%$ lower, but the upper-limit one is slightly higher 
$499(16 \%)$ than that for the meltwater. Sea ice in the Canada Basin may contain 500 terrigenous CDOM (Xie et al., 2014), which is a more efficient substrate of CO 501 photoproduction than marine CDOM of biological origin, especially in visible regime 502 (Zhang et al., 2006; White et al., 2010; Stubbins et al., 2011).

3.5. Relative contributions of $\mathrm{CDOM}$ and $\mathrm{POM}$ to $\mathrm{CO}$ in bottom sea ice

During vernal ice algal blooms, $\mathrm{CO}$ is enriched in the lowermost layer of firstyear sea ice in the western Canadian Arctic (Xie and Gosselin, 2005; Song et al., 2011). Xie and Gosselin (2005) proposed that CO photoproduction from CDOM, combined with slow microbial $\mathrm{CO}$ consumption, in the bottom ice may be an important mechanism underlying this $\mathrm{CO}$ enrichment. The present study indicates that $\mathrm{CO}$ photoproduction from ice algal-derived POM may play a significant role as well. Here we assessed the relative contributions of these two $\mathrm{CO}$ source pathways at station D43-1 in Song et al. (2011), based on the $\Phi_{\mathrm{CO}}$ spectra from this study, assuming that the selected ice algae are dominant species at this area during ice algal blooms (Poulin et al., 2011). The absorption spectrum of sea-ice CDOM used for this assessment was obtained from the study by Xie et al. (2014), and that of particles was retrieved according to the relationship between $a_{\mathrm{p}, \lambda}$ and $[\mathrm{Chl} a]$ reported by Ehn and Mundy (2013). This estimation can be mathematically expressed as:

$$
\begin{gathered}
P_{P O M, \lambda}=Q_{0, \lambda}^{\prime} \times\left(a_{p, \lambda} / a_{t}\right) \times\left(1-\exp \left(-a_{t} \times \mathrm{Z}\right)\right) \times \Phi_{p, \lambda} \\
P_{C D O M, \lambda}=Q_{0, \lambda}^{\prime} \times\left(a_{C D O M, \lambda} / a_{t}\right) \times\left(1-\exp \left(-a_{t} \times \mathrm{Z}\right)\right) \times \Phi_{C D O M, \lambda}
\end{gathered}
$$

where $P_{\mathrm{POM}, \lambda}$ and $P_{\mathrm{CDOM}, \lambda}$ denote $\mathrm{CO}$ photoproduction rates $\left(\mu \mathrm{mol} \mathrm{CO} \mathrm{m}^{-2} \mathrm{~d}^{-1} \mathrm{~nm}^{-1}\right)$ for POM and CDOM, respectively, $Q_{0, \lambda}^{\prime}$ (mol photons $\mathrm{m}^{-2} \mathrm{~d}^{-1} \mathrm{~nm}^{-1}$ ) is the in-ice spectral solar photon flux at the depth of $10 \mathrm{~cm}$ from the ice-water interface, $a_{\mathrm{t}, \lambda}\left(\mathrm{m}^{-1}\right)$ is the total absorption coefficient, i.e. the sum of $a_{\mathrm{CDOM}, \lambda}, a_{\mathrm{p}, \lambda}$ and the absorption 
coefficient of pure ice (Grenfell and Perovich, 1981; Perovich and Govoni, 1991), and $Z(\mathrm{~m})$ is the light pathlength of the bottommost $10-\mathrm{cm}$ sea ice layer. $Z$ is unknown due to the highly scattering property of sea ice (Ehn and Mundy, 2013; Katlein et al., 2014). Dividing Eq. 7 by Eq. 8 gives the ratio of $P_{\mathrm{POM}, \lambda}$ to $P_{\mathrm{CDOM}, \lambda}\left(R_{\mathrm{POM} / \mathrm{CDOM}, \lambda}\right)$ :

$$
R_{P O M / C D O M, \lambda}=\left(a_{p, \lambda} \times \Phi_{p, \lambda}\right) /\left(a_{C D O M, \lambda} \times \Phi_{C D O M, \lambda}\right)
$$

The $\Phi_{\mathrm{CO}}(\mathrm{EP})$ values are assigned to the parameters on the right-hand side of Eq. 9 in order to be in line with the spring bloom in the field.

$R_{\mathrm{POM} / \mathrm{CDOM}}$ is thus dictated by the ratios of $a_{\mathrm{p}, \lambda} / a_{\mathrm{CDOM}, \lambda}$ and $\Phi_{\mathrm{p}, \lambda} / \Phi_{\mathrm{CDOM}, \lambda}$. The ratio of $a_{\mathrm{p}, \lambda} / a_{\mathrm{CDOM}, \lambda}$ generally increased with increasing wavelength, with the values $<$ 1 at $\lambda<340 \mathrm{~nm}$ (Fig. 6A). Moreover, there is a broad shoulder between 340 and 560 $\mathrm{nm}$, which is mainly induced by the pigment absorption. The ratio of $\Phi_{\mathrm{p}, \lambda} / \Phi_{\mathrm{CDOM}, \lambda}$ first decreased with increasing wavelength, with the minima located at $345-375 \mathrm{~nm}$ depending on species, and then increased approximately exponentially at longer wavelength (Fig. 6B). The modeled results demonstrate that $R_{\text {POM/CDOM }}$ in bottom sea ice slightly decreases with wavelength from $300 \mathrm{~nm}$ to $\sim 330 \mathrm{~nm}$ and increases approximately exponentially with further increasing wavelength from $330 \mathrm{~nm}$ to 600 $\mathrm{nm}$ (Fig. 6C). $R_{\mathrm{POM} / \mathrm{CDOM}}$ is $>1$ within the entire wavelength range from $300 \mathrm{~nm}$ to 600 $\mathrm{nm}$ and for all cultures except $N$. frigida whose $R_{\mathrm{POM} / \mathrm{CDOM}}$ values are $<1$ (range: 0.64 to 1$)$ at $\lambda<345 \mathrm{~nm}$. Averaged on all cultures, $R_{\mathrm{POM} / \mathrm{CDOM}}$ increases from $2.1 \pm 1.2$ $(0.8-3.6)$ in the UVB to $6.9 \pm 5.4(3.7-15)$ in the UVA to $1.6 \times 10^{4} \pm 2.0 \times 10^{4}(510-4.3$ $\times 10^{4}$ ) in the visible (Fig. 7). Given that the transmittance and hence the solar irradiance are highest at $\sim 500 \mathrm{~nm}$ in the bottom sea ice (Ehn et al., 2008), particles far exceed CDOM in contributing $\mathrm{CO}$ photoproduction. The results are similar when the upper-limits of $\Phi_{\mathrm{CDOM}}(\mathrm{EP})$ are used for calculating $R_{\mathrm{POM} / \mathrm{CDOM}, \lambda}$. However, $R_{\mathrm{POM} / \mathrm{CDOM}, \lambda}$ based on the upper-limits of $\Phi_{\mathrm{CDOM}}(\mathrm{EP})$ is $19 \%-77 \%$ lower than those 
calculated from the lower-limits of $\Phi_{\mathrm{CDOM}}(\mathrm{EP})$, depending on species and wavelength. Although $R_{\mathrm{POM} / \mathrm{CDOM}}$ was estimated only for station D43-1, the general conclusion should hold for the rest of the western Canadian Arctic during spring blooms of ice algae, since the ratio of $a_{\mathrm{p}} / a_{\mathrm{CDOM}, \lambda}$ fell in a relatively small range (e.g. 1.2-4.8 at 330 nm) (Ehn and Mundy, 2013; Xie et al., 2014).

Notably, $\Phi_{\mathrm{CDOM}, \lambda}$ used in this study likely overestimates $R_{\mathrm{POM} / \mathrm{CDOM}}$, since $\Phi_{\mathrm{CDOM}}$ of the cultures are usually lower than those of sea-ice meltwater at $\lambda>350 \mathrm{~nm}$ (Fig. 5). Furthermore, $\Phi_{\mathrm{p}, \lambda}$ of the cultures may also cause overestimation, given that sea ice may contain terrigenous particles (Rachold et al., 2004), which are less efficient than marine-derived POM at CO photoproduction (Song et al., 2013). On the other hand, the relative contributions of POM and CDOM were assessed only for the wavelength range from $300 \mathrm{~nm}$ to $600 \mathrm{~nm}$, which excludes the POM-photosensitive band of 600-700 nm (Fig. 4). The omission of this part underestimates $R_{\mathrm{POM} / \mathrm{CDOM}}$.

\section{Summary}

We detected CO photoproduction from ice algal-derived CDOM and particles, with the particle-based pathway extending into the much longer wavelengths $(>600 \mathrm{~nm})$ than the CDOM-based one. The magnitude and shape of the AQY spectra of CO photoproduction from particles were dependent on ice algal species and growth stage. The particle-based CO AQY was more than several times higher than the CDOMbased one, irrespective of the ice algal species and growth stage, with the difference increasing with increasing wavelength. Particles are expected to dominate over $\mathrm{CDOM}$ in controlling $\mathrm{CO}$ photoproduction in bottom sea ice during ice algal blooms due to a combination of much higher photoreactivity of POM relative to CDOM at visible wavelengths, higher transmission of visible radiation in sea ice, and higher 
ratios of particle to CDOM absorption.

\section{Acknowledgements}

We thank C. Lovejoy, A. R. Juhl and M. Gosselin for providing the parent ice algal cultures, M. Simard for DOC analysis, and J. K. Ehn for offering the ice transmittance data. This study was supported by grants from Natural Science and Engineering Research Council of Canada and National Science Foundation of China (41376081). GS was supported by graduate scholarships from the Institut des sciences de la mer de Rimouski (ISMER) and Fonds de recherche du Québec - Nature et technologies (FRQNT).

\section{References}

Babin, M., Stramski, D., Ferrari, G.M., Claustre, H., Bricaud, A., Obolensky, G., Hoepffner, N., 2003. Variations in the light absorption coefficients of phytoplankton, nonalgal particles, and dissolved organic matter in coastal waters around Europe. J. Geophys. Res. 108(C7), 3211, doi:10.1029/2001JC000882.

Berges, J.A., Franklin, D.J., Harrison, P.J., 2001. Evolution of an artificial seawater medium: improvements in enriched seawater, artificial water over the last two decades. J. Phycol. 37, 1138-1145.

Buiteveld, H., Hakvoort, J.M.H., Donze, M., 1994. The optical properties of pure water, in: Jaffe, J.S. (Ed.) SPIE proceeding on ocean optics XII. The Society of Photo-Optical Instrumentation Engineers, pp. 174-183.

Conrad, R., Seiler, W., 1980. Photooxidative production and microbial consumption of carbon monoxide in seawater. FEMS Microbiol. Lett. 9, 61-64.

Doxaran, D., Ehn, J., Bélanger, S., Matsuoka, A., Hooker, S., Babin, M., 2012. Optical characterization of suspended particles in the Mackenzie River plume (Canadian Arctic Ocean) and implications for ocean colour remote sensing. Biogeosciences 9, 3213-3229, doi:10.5194/bg-9-3213-2012.

Ehn, J.K., Mundy, C.J., Barber, D.G., 2008. Bio-optical and structural properties inferred from irradiance measurements within the bottommost layers in an Arctic 

landfast sea ice cover. J. Geophys. Res. 113, C03S03, doi:10.1029/2007JC004194. Ehn, J.K., Mundy, C.J., 2013. Assessment of light absorption within highly scattering bottom sea ice from under-ice light measurements: Implications for Arctic ice algae primary production. Limnol. Oceanogr. 58(3), 893-902.

Estapa, M.L., Mayer, L.M., Boss, E., 2012. Rate and apparent quantum yield of photodissolution of sedimentary organic matter. Limnol. Oceanogr. 57, 1743-1756.

Gao, H., Zepp, R.G., 1998. Factors influencing photoreactions of dissolved organic matter in a coastal river of the southeastern United States. Environ. Sci. Technol. 32, 2940-2946.

Gosink, T.A., Pearson, J.G., Kelley, J.J., 1976. Gas movement through sea ice. Nature $263,41-42$.

Gosselin, M., Levasseur, M., Wheeler, P.A., Horner, R.A., Booth, B.C., 1997. New measurements of phytoplankton and ice algal production in the Arctic Ocean. Deep-Sea Res., Part II 44(8), 1623-1644.

Grenfell, T.C., Perovich, D.K., 1981. Radiation absorption coefficients of polycrystalline ice from 400-1400 nm. J. Geophys. Res. 86(C8), 7447-7450.

Gros, V., Peeken, I., Bluhm, K., Zöllner, E., Sarda-Esteve, R., Bonsang, B., 2009. Carbon monoxide emissions by phytoplankton: evidence from laboratory experiments. Environ. Chem. 6, 369-379, doi:10.1071/EN09020.

Gueymard, C.A., 2001. Parameterized transmittance model for direct beam and circumsolar spectral irradiance. Sol. Energy 71, 325-346.

Holm-Hansen, O., Lorenzen, C.J., Holmes, R.W., Strickland, J.D., 1965. Fluorometric determination of chlorophyll. J. Cons. Int. Explor. Mer 30, 3-15.

Hu, C., Muller-Karger, F.E., Zepp, R.G., 2002. Absorbance, absorption coefficient, and apparent quantum yield: A comment on common ambiguity in the use of these optical concepts. Limnol. Oceanogr. 47, 1261-1267.

Katlein, C., Nicolaus, M., Petrich, C., 2014. The anisotropic scattering coefficient of sea ice. J. Geophys. Res. Oceans 119, 842-855, doi:10.1002/2003JC009502.

Koehler, B., Broman, E., Tranvik, L.J., 2016. Apparent quantum yield of photochemical dissolved organic carbon mineralization in lakes. Limnol. Oceanogr., 61, 2207-2221.

Levasseur, M., 2013. Impact of Arctic meltdown on the microbial cycling of sulphur. Nature Geoscience 6, 691-700, doi:10.1038/NGEO1910.

Levasseur, M., Gosselin, M., Michaud, S., 1994. A new source of dimethylsulfide 
(DMS) for the arctic atmosphere: ice diatoms. Mar. Biol. 121, 381-387.

Leymarie, E., Doxaran, D., Babin, M., 2010. Uncertainties associated to measurements of inherent optical properties in natural waters. Appl. Opt. 49, 54155436.

Lovely, A., Loose, B., Schlosser, P., McGillis, W., Zappa, C., Perovich, D., Brown, S., Morell, T., Hsueh, D., Friedrich, R., 2015. The gas transfer through polar sea ice experiment: Insights into the rates and pathways that determine geochemical fluxes. J. Geophys. Res. Oceans 120, 8177-8194, doi:10.1002/2014JC010607.

Miller, G.C., Zepp, R.G, 1979. Effects of suspended sediments on photolysis rates of dissolved pollutants. Water Res. 13, 453-459.

Moran, M.A., Miller, W.L., 2007. Resourceful heterotrophs make the most of light in the coastal ocean. Nature Reviews Microbiol. 5, 1-9.

Parsons, T.R., Maita, Y., Lalli, C.M., 1984. A Manual of Chemical and Biological Methods for Seawater Analysis, Pergamon, New York.

Perovich, D.K., Govoni, J.W., 1991. Absorption coefficients of ice from 250 to 400 nm. Geophys. Res. Lett. 18(7), 1233-1235.

Pope, R.M., Fry, E.S., 1997. Absorption spectrum (380-700 nm) of pure water. 2. Integrating cavity measurements. Appl. Opt. 36, 8710-8723.

Poulin, M., Daugbjerg, N., Gradinger, R., Ilyash, L., Ratkova, T., von Quillfeldt, C.H., 2011. The pan-Arctic biodiversity of marine pelagic and sea-ice unicellular eukaryotes: a first-attempt assessment. Mar. Biodiv. 41, 13-28, doi:10.1007/s112526-010-0058-8.

Rachold, V., Eicken, H., Gordeev, V.V., Grigoriev, M.N., Hubberten, H.-W., Lisitzin, A.P., Shevchenko, V.P., Schirrmeister, L., 2004. Modern terrigenous organic carbon input to the Arctic Ocean, in: Stein, R., Macdonald, R.W. (Eds), The organic carbon cycle in the Arctic Ocean, Springer, New York, pp. 33-54.

Randall, K., Scarratt, M., Levasseur, M., Michaud, S., Xie, H., Gosselin, M., 2012. First measurements of nitrous oxide in Arctic sea ice. J. Geophys. Res. 117, C00G15, doi:10.1029/2011JC007340.

Riedel, A., Michel, C., Gosselin, M., LeBlanc, B., 2008. Winter-spring dynamics in sea-ice carbon cycling in the coastal Arctic Ocean. J. Mar. Syst. 74, 918-932, doi:10.1016/j.jmarsys.2008.01.003.

Röttgers, R., Gehnke, S., 2012. Measurement of light absorption by aquatic particles: improvement of the quantitative filter technique by use of an integrating sphere 
approach. Appl. Opt. 51, 1336-1351.

Smith, R.E.H., Gosselin, M., Kudoh, S., Robineau, B., Taguchi, S., 1997. DOC and its relationship to algae in bottom ice communities. J. Mar. Syst. 11, 71-80.

Song, G., Xie, H., Aubry, C., Zhang, Y., Gosselin, M., Mundy, C.J., Philippe, B., Papakyriakou, T.N., 2011. Spatiotemporal variations of dissolved organic carbon and carbon monoxide in first-year sea ice in the western Canadian Arctic. J. Geophys. Res. 116, C00G05, doi:10.1029/2010JC006867.

Song, G., Xie, H., Bélanger, S., Leymarie, E., Babin, M., 2013. Spectrally resolved efficiencies of carbon monoxide (CO) photoproduction in the western Canadian Arctic: particles versus solutes. Biogeosciences 10, 3731-3748, doi:10.5194/bg10-3731-2013.

Song, G., Richardson, J.D., Werner, J.P., Xie, H., Kieber, D.J., 2015. Carbon monoxide photoproduction from particles and solutes in the Delaware Estuary under contrasting hydrological conditions. Environ. Sci. Technol. 49, 1404814056.

Stubbins, A., Hubbard, V., Uher, G., Aiken, G., Law, C.S., Upstill-Goddard, R.C., Mopper, K., 2008. Relating carbon monoxide photoproduction to dissolved organic matter functionality. Environ. Sci. Technol. 42, 3271-3276.

Stubbins, A., Law, C.S., Uher, G., Upstill-Goddard, R.C., 2011. Carbon monoxide apparent quantum yields and photoproduction in the Tyne estuary. Biogeosciences 8, 703-713.

Thompson, A.M., 1992. The oxidizing capacity of the Earth's atmosphere: Probable past and future changes. Science 256, 1157-1165.

Turner, S.M., Nightingale, P.D., Broadgate, W., Liss, P.S., 1995. The distribution of dimethyl sulphide and dimethylsulphoniopropionate in Antarctic waters and sea ice. Deep-Sea Res., Part II 42(4-5), 1059-1080.

von Quillfeldt, C.H., Ambrose Jr., W.G., Clough, L.M., 2003. High number of diatom species in first-year ice from the Chukchi Sea. Polar Biol. 26, 806-818, doi:10.1007/s00300-003-0549-1.

White, E.M., Kieber, D.J., Sherrard, J., Miller, W.L., Mopper, K., 2010. Carbon dioxide and carbon monoxide photoproduction quantum yields in the Delaware Estuary. Mar. Chem. 118, 11-21.

Xie, H., Andrews, S.S., Martin, W.R., Miller, J., Ziolkowski, L., Taylor, C.D., Zafiriou, O.C., 2002. Validated methods for sampling and headspace analysis of carbon 
monoxide in seawater. Mar. Chem. 77, 93-108.

Xie, H., Aubry, C., Zhang, Y., Song, G., 2014. Chromophoric dissolved organic matter $(\mathrm{CDOM})$ in first-year sea ice in the western Canadian Arctic. Mar. Chem. 165, 2535.

Xie, H., Gosselin, M., 2005. Photoproduction of carbon monoxide in first-year sea ice in Franklin Bay, southeastern Beaufort Sea. Geophys. Res. Lett., 32, L12606, doi:10.1029/2005GL022803.

Xie, H., Zhang, Y., Lemarchand, K., Poulin, P., 2009a. Microbial carbon monoxide uptake in the St. Lawrence estuarine system. Mar. Ecol. Prog. Ser. 389, 17-29.

Xie, H., Bélanger, S., Demers, S., Vincent, W.F., Papakytiakou, T.N., 2009b. Photobiogeochemical cycling of carbon monoxide in the southeastern Beaufort Sea in spring and autumn. Limnol. Oceanogr. 54, 234-249.

Zafiriou, O.C., 1974. Sources and reactions of hydroxyl and daughter radicals in seawater. J. Geophys. Res. 79, 4491-4497.

Zafiriou, O.C., Andrews, S.S., Wang, W., 2003. Concordant estimates of oceanic carbon monoxide source and sink process in the Pacific yield a balanced global "blue-water" CO budget. Global Biogeochem. Cycles 17(1), 1015, doi:10.1029/2001GB001638.

Zafiriou, O.C., True, M.B, 1979. Nitrate photolysis in seawater by sunlight. Mar. Chem. 8, 33-42.

Zafiriou, O.C., True, M.B., Hayon, E., 1987. Consequence of OH radical reaction in seawater: formation and decay of Br2- ion radical, in: Zika, R.G., Cooper,W.J. (Eds.), Photochemistry of Environmental Aquatic Systems. American Chemical Society, Washington, DC, pp. 89-105.

Zepp, R.G., Erickson III, D.J., Paul, N.D., Sulzberger, B., 2011. Effects of solar UV raidaiton and climate change on biogeochemical cycling: interactions and feedbacks. Photochem. Photobiol. Sci. 10, 261-279, doi:10.1039/c0pp90037k.

Zhang, Y., Xie, H., Chen, G., 2006. Factors affecting the efficiency of carbon monoxide photoproduction in the St. Lawrence Estuarine system (Canada). Environ. Sci. Technol. 40, 7771-7777. 


\section{Figure captions}

Fig. 1. Examples of absorption spectra of particles (A: P. taeniata; B: NIAA) and CDOM (C: P. taeniata; D: NIAA). Particle absorption spectra refer to those in the particle-containing artificial seawater samples prepared for the irradiation experiments, while CDOM absorption spectra refer to those in the cultures used for preparing the particle-containing artificial seawater samples (see details in the text). EP and SP stand for exponential phase and senescent phase, respectively; $a_{\mathrm{p}}$ and $a_{\text {nap }}$ denote absorption coefficients of total particles and non-algal particles, respectively. Note that the vertical scales for the four panels are different.

Fig. 2. [CO] in NIAA particle-containing samples versus exposure time under fullspectrum irradiation (A) and [CO] in dark controls of particle-containing samples versus incubation time for all the cultures (B). In panel A, error bars, which are smaller than the symbols, represent the range of the duplicate [CO] measurements. Data for cultures other than NIAA are not shown but also show linear increases in [CO] with irradiation time. In panel B, data shown are for exponential phase (EP) only; data for the senescent phase (SP) are not shown but similar in pattern, with lower slopes (i.e. production rates).

Fig. 3. Examples of $\mathrm{CO}$ photoproduction from $\mathrm{CDOM}$ and particles collected from the culture of $A$. septentrionalis as a function of the nominal $50 \%$ cutoff wavelength.

Fig. 4. Spectra of $\Phi_{\mathrm{CDOM}, \lambda}$ and $\Phi_{\mathrm{p}, \lambda}$ obtained in the present study. In panel (A), spectra of $\Phi_{\mathrm{CDOM}, \lambda}(\mathrm{EP})$ and $\Phi_{\mathrm{CDOM}, \lambda}(\mathrm{SP})$ are overlapped. No data available for $\Phi_{\mathrm{p}, \lambda}(\mathrm{SP})$ of $N$. frigida. 
766 Fig. 5. Comparison of the mean $\Phi_{\mathrm{p}, \lambda}$ spectra obtained in this study with those reported 767 by Song et al. (2013) for surface and deep-chlorophyll $a$-maximum (DCM) water 768 samples collected from Canada Basin (A) and comparison of the mean lower- and 769 upper-limits of $\Phi_{\mathrm{CDOM}, \lambda}$ spectra with that for the bottommost 10 -cm layer of sea ice 770 collected from station D43-1 in the study of Song et al. (2011) (B).

771

772 Fig. 6. The ratios of $a_{\mathrm{p}}$ to $a_{\mathrm{CDOM}}(\mathrm{A})$ and $\Phi_{\mathrm{p}}$ to $\Phi_{\mathrm{CDOM}}(\mathrm{B})$, and the modeled ratio of $773 P_{\mathrm{POM}, \lambda}$ to $P_{\mathrm{CDOM}, \lambda}\left(R_{\mathrm{POM} / \mathrm{CDOM}}\right)(\mathrm{C})$ as a function of wavelength in bottom sea ice for 774 each culture. The lower-limits of $\Phi_{\mathrm{CDOM}, \lambda}$ were used for calculation.

775

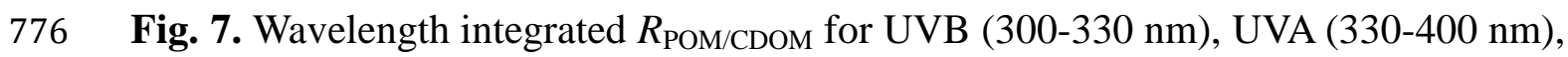
777 visible (400-600 nm), and full-spectrum (300-600 nm) radiations for each culture. The 778 lower-limits of $\Phi_{\lambda}$ of CDOM were used for the calculation. 
Table 1 Incubation conditions of selected ice algae

\begin{tabular}{|c|c|c|c|c|c|c|c|}
\hline \multirow{2}{*}{ Ice algae } & \multirow{2}{*}{$\begin{array}{l}\text { CCMP } \\
\text { strain }\end{array}$} & \multirow{2}{*}{ Taxon } & \multicolumn{2}{|c|}{$\operatorname{Cell~size}^{\mathrm{a}}(\mu \mathrm{m})$} & \multicolumn{2}{|l|}{ Light } & \multirow{2}{*}{$\begin{array}{l}\text { Incubation } \\
\text { duration } \\
\text { (d) }\end{array}$} \\
\hline & & & Length & Width & Intensity $\left(\mu \mathrm{mol} \mathrm{m} \mathrm{m}^{-2} \mathrm{~s}^{-1}\right)$ & Cycle & \\
\hline Pauliella taeniata ${ }^{\mathrm{b}}$ & 1115 & Pennate diatoms & $20-22$ & $5-7$ & $60-70$ & $14: 10$ & 166 \\
\hline Attheya septentrionalis & 2083 & Centric diatoms & $14-20$ & $3-4$ & 40 & Continuous & 94 \\
\hline Nitzschia frigida & NA & Pennate diatoms & NA & NA & 40 & Continuous & 124 \\
\hline Natural ice algal assemblage & NA & NA & NA & NA & 40 & Continuous & 120 \\
\hline
\end{tabular}

${ }^{\mathrm{a}}$ Cell sizes of P. taeniata and A. septentrionalis are obtained from the webpage of National Center for Marine Algae and Microbiota

(NCMA) (https://ncma.bigelow.org). No size data is available for $N$. frigida and natural ice algal assemblage (NIAA).

${ }^{\mathrm{b}}$ Incubation conditions for P. taeniata were the same as those adopted by NCMA and for other species (including NIAA) followed those employed by the providers of the ice algae (C. Lovejoy and A. R. Juhl, personal communications). 
Table 2 Biological, chemical, and optical properties of particles (GF/F filtered) and $\operatorname{CDOM}\left(0.2-\mu \mathrm{m}\right.$ filtered) samples. Here $[\mathrm{Chl} a], a_{\mathrm{p}, 443}$, and $a_{\mathrm{phy}, 443} / a_{\mathrm{p}, 443}$ refer to the mean values of duplicate dark controls for samples of particles dispersed into the artificial seawater (see text for details). [DOC] and CDOM absorption spectra of the medium were determined only for the exponential phase and did not show significant variations during the incubation ( $\mathrm{Li}$ et al., unpublished data). EP: exponential phase; SP: senescent phase; ND: no data is available.

\begin{tabular}{|c|c|c|c|c|c|}
\hline $\begin{array}{l}\text { Growth } \\
\text { phase }\end{array}$ & $\mathrm{f} / 2$ medium & P. taeniata & A. septentrionalis & N. frigida & NIAA \\
\hline & \multicolumn{5}{|c|}{ Chl $a\left(\mu \mathrm{g} \mathrm{L}^{-1}\right)$} \\
\hline EP & ND & 73.7 & 60.6 & 15.0 & 92.7 \\
\hline \multirow[t]{2}{*}{$\mathrm{SP}$} & ND & 22.6 & 13.0 & ND & 12.0 \\
\hline & \multicolumn{5}{|c|}{$a_{\mathrm{p}, 443}\left(\mathrm{~m}^{-1}\right)$} \\
\hline $\mathrm{EP}$ & ND & 0.93 & 1.10 & 0.29 & 1.33 \\
\hline \multirow[t]{2}{*}{$\mathrm{SP}$} & ND & 0.85 & 0.68 & ND & 0.13 \\
\hline & \multicolumn{5}{|c|}{$a_{\mathrm{phy}, 443} / a_{\mathrm{p}, 443}$} \\
\hline $\mathrm{EP}$ & ND & 0.92 & 0.92 & 0.89 & 0.85 \\
\hline \multirow[t]{2}{*}{ SP } & ND & 0.84 & 0.86 & ND & 0.47 \\
\hline & \multicolumn{5}{|c|}{$\mathrm{DOC}\left(\mu \mathrm{mol} \mathrm{L}^{-1}\right)$} \\
\hline EP & 283.3 & 410.0 & 322.5 & 340.0 & 536.7 \\
\hline \multirow[t]{2}{*}{ SP } & ND & 1542 & 603.3 & 439.2 & 1642 \\
\hline & \multicolumn{5}{|c|}{$a_{\mathrm{CDOM}, 330}\left(\mathrm{~m}^{-1}\right)$} \\
\hline $\mathrm{EP}$ & 1.45 & 1.67 & 1.67 & 1.70 & 3.02 \\
\hline SP & ND & 7.57 & 2.94 & 2.17 & 6.09 \\
\hline
\end{tabular}


Table 3 Fitted parameters for Eq. 4 (particles) and Eq. 5 (CDOM) in the text, along with $\bar{\Phi}$. NA: no data available.

\begin{tabular}{|c|c|c|c|c|c|c|c|c|}
\hline \multirow{3}{*}{ Ice algae } & \multicolumn{8}{|c|}{ Particles } \\
\hline & \multicolumn{4}{|c|}{ Exponential phase } & \multicolumn{4}{|c|}{ Senescent phase } \\
\hline & $\begin{array}{l}m_{1} \\
\times 10^{10} \\
\end{array}$ & $m_{2}$ & $m_{3}$ & $\begin{array}{l}\bar{\Phi} \\
\times 10^{6}\end{array}$ & $\begin{array}{l}m_{1} \\
\times 10^{10} \\
\end{array}$ & $m_{2}$ & $m_{3}$ & $\begin{array}{l}\bar{\Phi} \\
\times 10^{6} \\
\end{array}$ \\
\hline P. taeniata & 1883 & 805.1 & -209.4 & 10.6 & 0.92 & 3965 & -45.8 & 5.75 \\
\hline A. septentrionalis & 38.1 & 2024 & -116.6 & 3.40 & 3.04 & 3611 & -43.2 & 5.51 \\
\hline N. frigida & 291.1 & 987.8 & -193.9 & 2.83 & NA & & & \\
\hline \multirow[t]{4}{*}{ NIAA } & 2249 & 641.6 & -222.3 & 6.74 & 181.1 & 2271 & -91.2 & 18.2 \\
\hline & \multicolumn{8}{|c|}{ CDOM } \\
\hline & \multicolumn{3}{|c|}{ Exponential phase } & \multicolumn{4}{|c|}{ Senescent phase } & \\
\hline & $\begin{array}{c}m_{4} \\
\times 10^{6} \\
\end{array}$ & & $m_{5}$ & $\begin{array}{c}\bar{\Phi} \\
\times 10^{6} \\
\end{array}$ & $\begin{array}{c}m_{4} \\
\times 10^{6} \\
\end{array}$ & & $m_{5}$ & $\begin{array}{c}\bar{\Phi} \\
\times 10^{6} \\
\end{array}$ \\
\hline Medium & 104.4 & & -0.058 & 0.42 & & & NA & \\
\hline P. taeniata & 238.6 & & -0.044 & 1.99 & 221.9 & & .043 & 1.88 \\
\hline A. septentrionalis & 105.5 & & -0.033 & 1.79 & 227.8 & & .047 & 1.94 \\
\hline N. frigida & 306.3 & & -0.047 & 2.18 & 137.8 & & .043 & 1.18 \\
\hline NIAA & 136.7 & & -0.027 & 3.61 & 159.2 & & .032 & 2.91 \\
\hline
\end{tabular}


A)

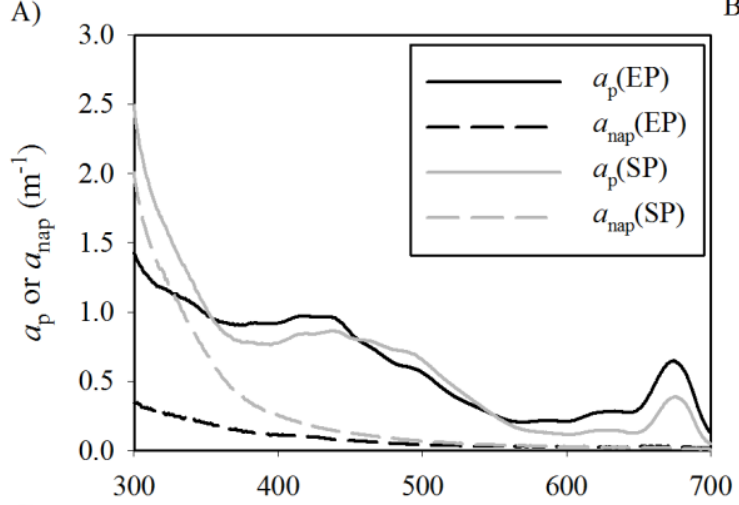

C)

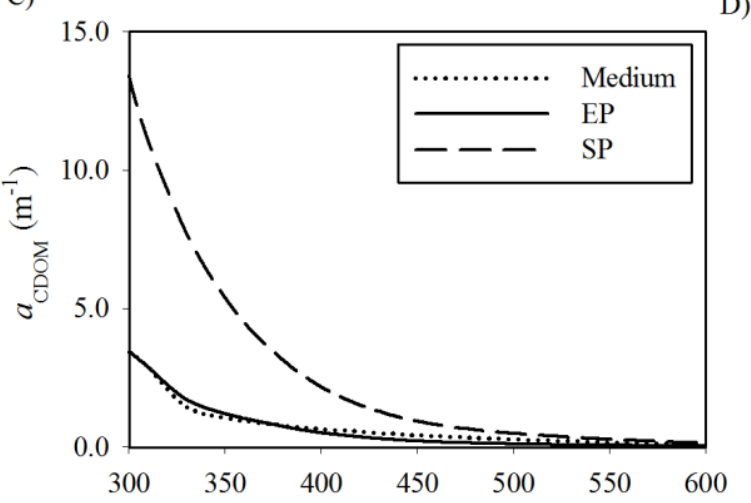

B)

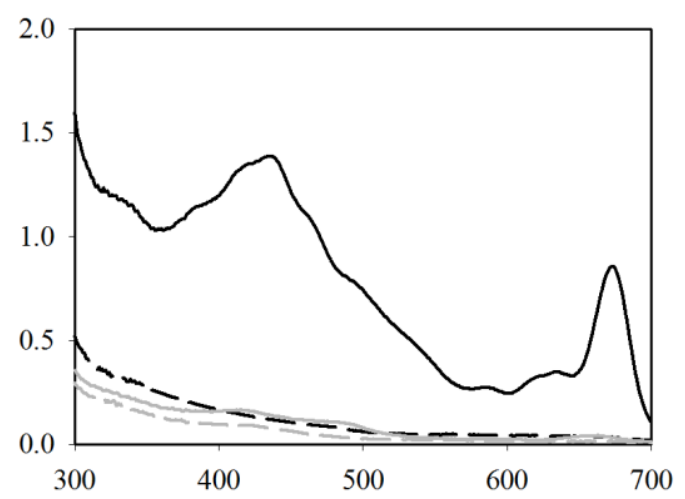

D)

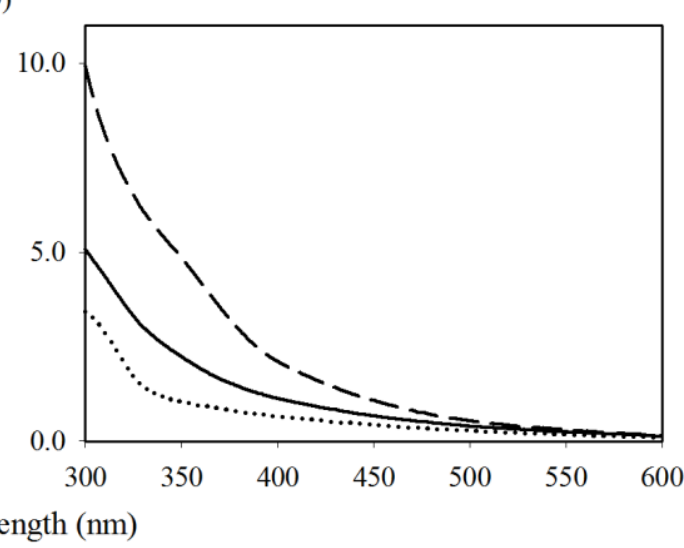

Fig. 1. Examples of absorption spectra of particles (A: P. taeniata; B: NIAA) and CDOM (C: P. taeniata; D: NIAA). Particle absorption spectra refer to those in the particle-containing artificial seawater samples prepared for the irradiation experiments, while CDOM absorption spectra refer to those in the cultures used for preparing the particle-containing artificial seawater samples (see details in the text). EP and SP stand for exponential phase and senescent phase, respectively; $a_{\mathrm{p}}$ and $a_{\text {nap }}$ denote absorption coefficients of total particles and non-algal particles, respectively. Note that the vertical scales for the four panels are different. 

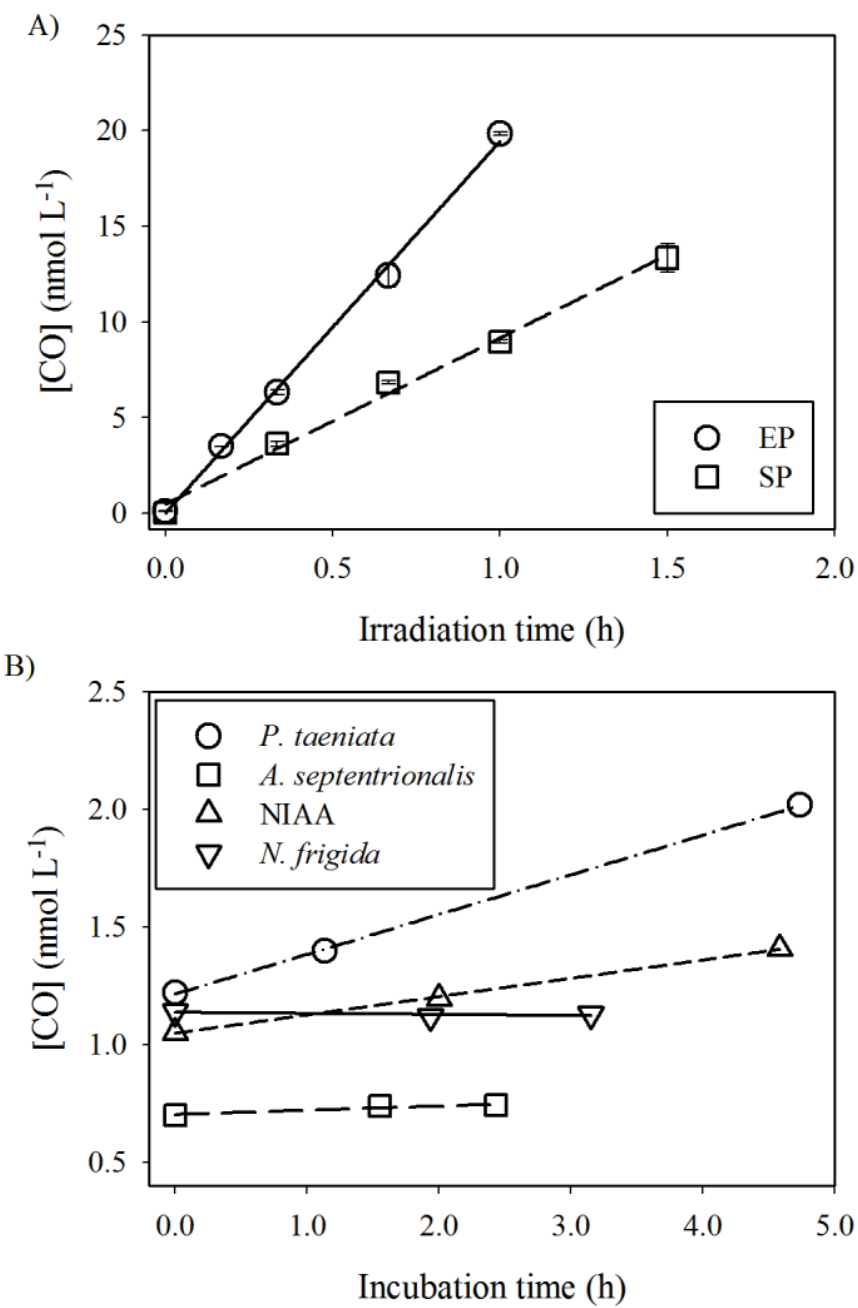

Fig. 2. [CO] in NIAA particle-containing samples versus exposure time under fullspectrum irradiation (A) and [CO] in dark controls of particle-containing samples versus incubation time for all four cultures (B). In panel A, error bars, which are smaller than the symbols, represent the range of the duplicate [CO] measurements. Data for cultures other than NIAA are not shown but also show linear increases in [CO] with irradiation time. In panel B, data shown are for exponential phase (EP) only; data for the senescent phase (SP) are not shown but similar in pattern, with lower slopes (i.e. production rates). 


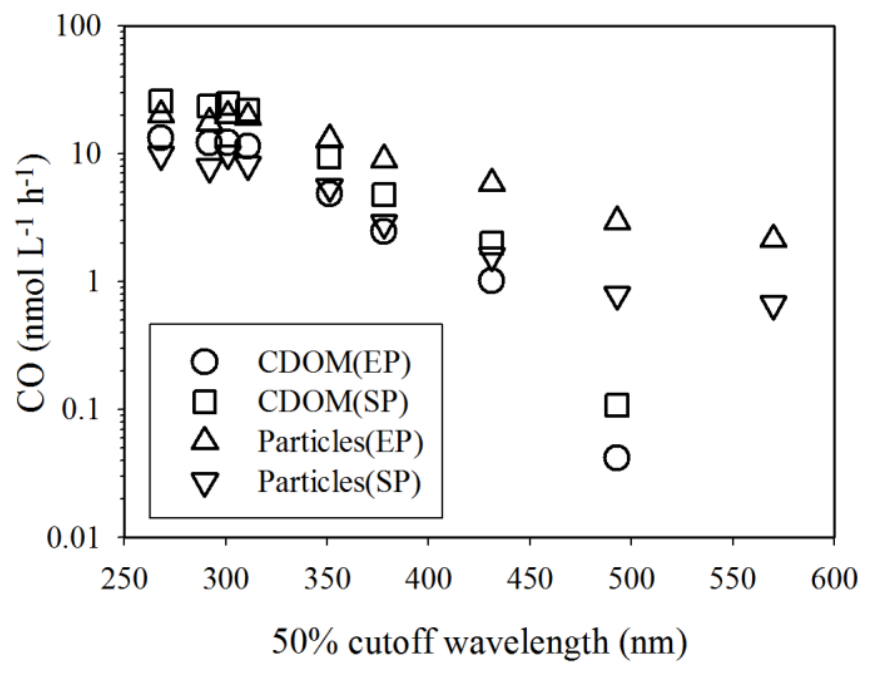

Fig. 3. Examples of $\mathrm{CO}$ photoproduction from $\mathrm{CDOM}$ and particles collected from the culture of A. septentrionalis as a function of the nominal $50 \%$ cutoff wavelength. 

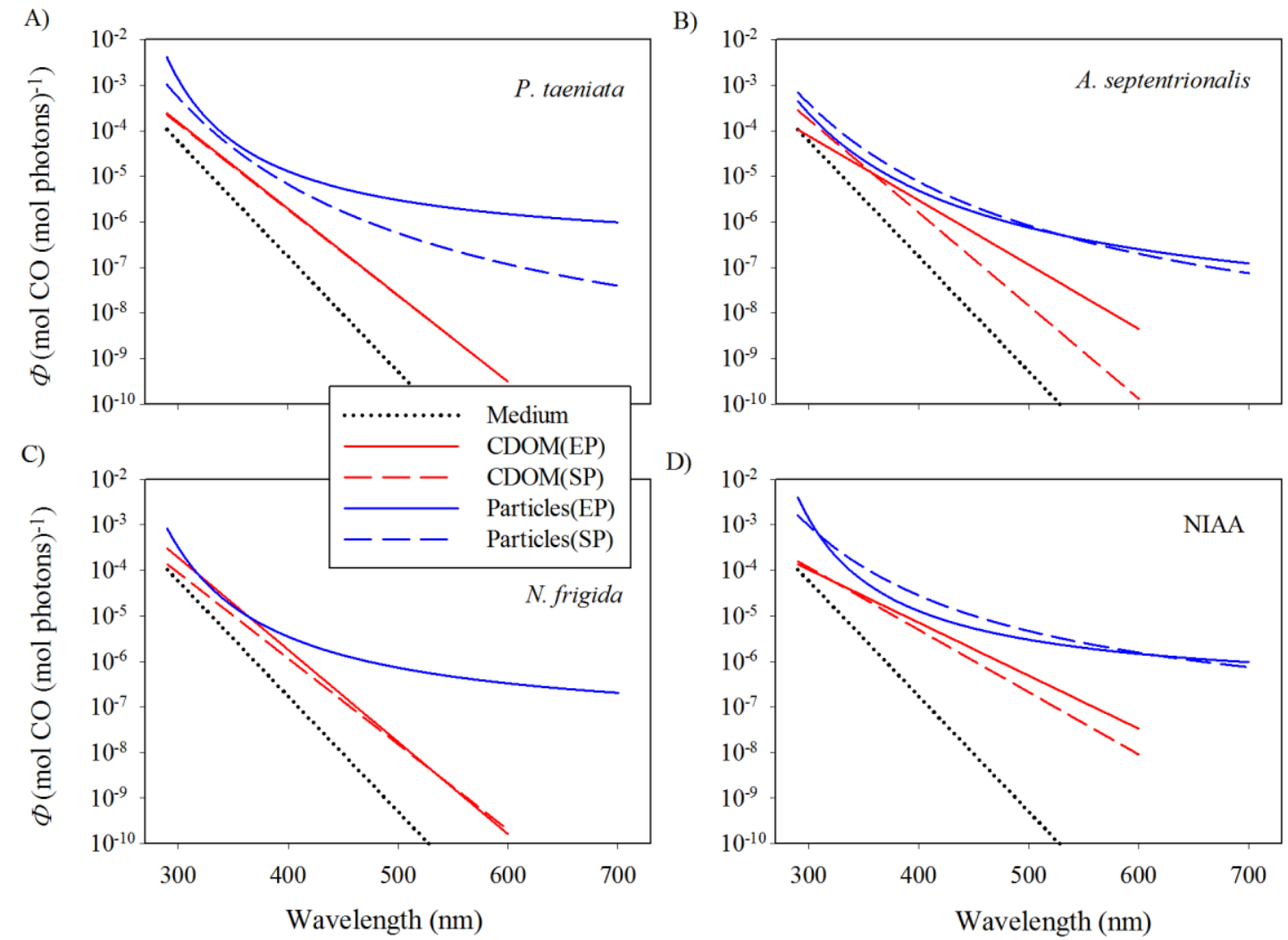

Fig. 4. Spectra of $\Phi_{\mathrm{CDOM}, \lambda}$ and $\Phi_{\mathrm{p}, \lambda}$ obtained in the present study. In panel (A), spectra of $\Phi_{\mathrm{CDOM}, \lambda}(\mathrm{EP})$ and $\Phi_{\mathrm{CDOM}, \lambda}(\mathrm{SP})$ are overlapped. No data available for $\Phi_{\mathrm{p}, \lambda}(\mathrm{SP})$ of $N$. frigida. 

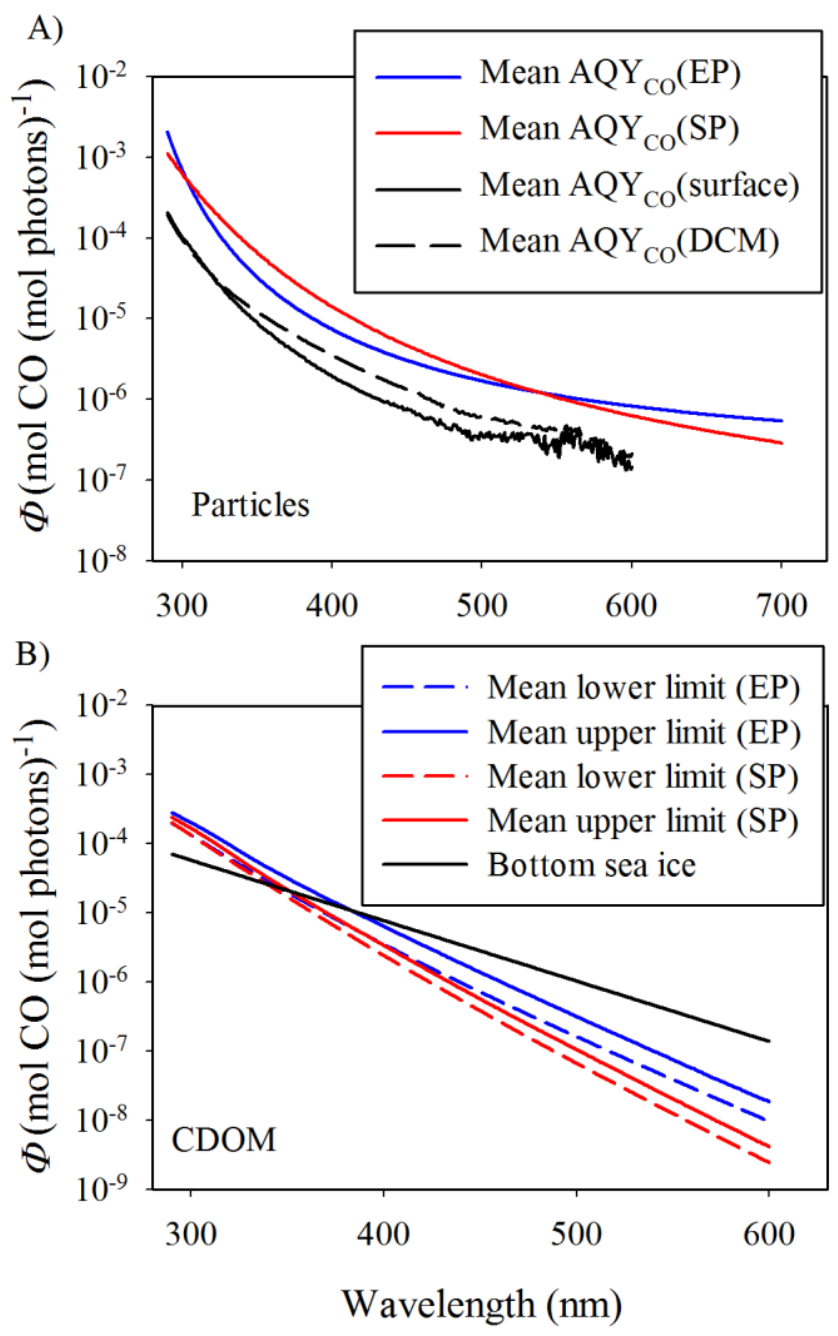

Fig. 5. Comparison of the mean $\Phi_{\mathrm{p}, \lambda}$ spectra obtained in this study with those reported by Song et al. (2013) for surface and deep-chlorophyll $a$-maximum (DCM) water samples collected from Canada Basin (A) and comparison of the mean lower- and upper-limits of $\Phi_{\mathrm{CDOM}, \lambda}$ spectra with that for the bottommost 10 -cm layer of sea ice collected from station D43-1 in the study of Song et al. (2011) (B). 

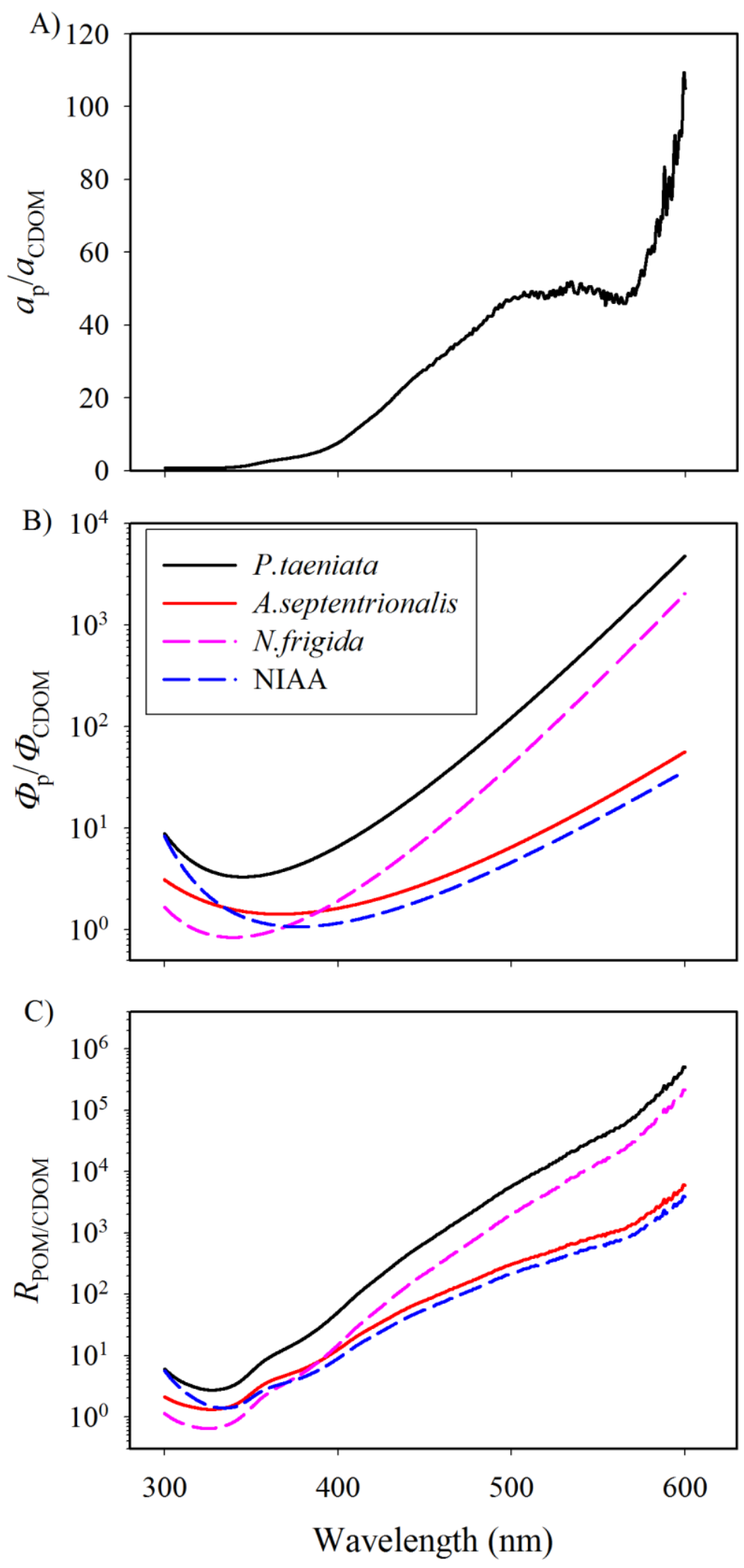

Fig. 6. The ratios of $a_{\mathrm{p}}$ to $a_{\mathrm{CDOM}}(\mathrm{A})$ and $\Phi_{\mathrm{p}}$ to $\Phi_{\mathrm{CDOM}}(\mathrm{B})$, and the modeled ratio of $P_{\mathrm{POM}, \lambda}$ to $P_{\mathrm{CDOM}, \lambda}\left(R_{\mathrm{POM} / \mathrm{CDOM}}\right)(\mathrm{C})$ as a function of wavelength in bottom sea ice for each culture. The lower-limits of $\Phi_{\mathrm{CDOM}, \lambda}$ were used for calculation. 


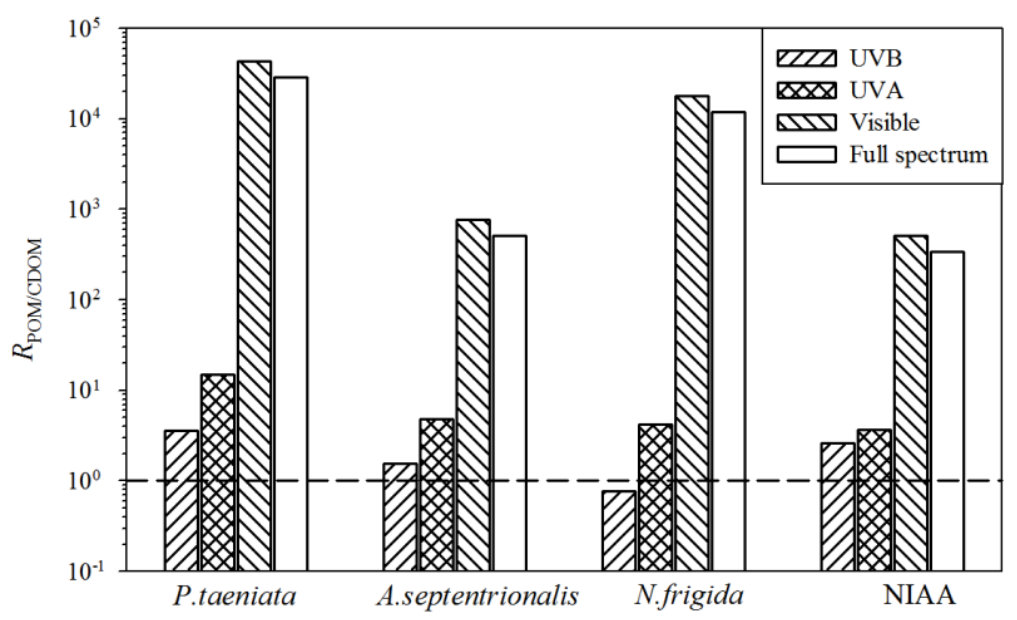

Fig. 7. Wavelength integrated $R_{\mathrm{POM} / \mathrm{CDOM}}$ for UVB (300-330 nm), UVA (330-400 nm), visible $(400-600 \mathrm{~nm})$, and full-spectrum $(300-600 \mathrm{~nm})$ radiations for each culture. The lower-limits of $\Phi_{\lambda}$ of CDOM were used for the calculation. 


\section{Appendix A}

Table A1 List of symbols and abbreviations

\begin{tabular}{|c|c|c|}
\hline Abbreviation & Meaning & \\
\hline$\overline{\mathrm{AQY}}$ & Apparent quantum yield & \\
\hline ASW & Artificial seawater & \\
\hline CDOM & Chromophoric dissolved organic matter & \\
\hline Chl $a$ & Chlorophyll $a$ & \\
\hline $\mathrm{CO}$ & Carbon monoxide & \\
\hline DOC & Dissolved organic carbon & \\
\hline DOM & Dissolved organic matter & \\
\hline EP & Exponential phase & \\
\hline NIAA & Natural ice algal assemblage & \\
\hline PAR & Photosynethetically available radiation & \\
\hline POC & Particulate organic carbon & \\
\hline POM & Particulate organic matter & \\
\hline SP & Senescent phase & \\
\hline UVA & Ultraviolet-A (320-400 nm) & \\
\hline UVB & Ultraviolet-B (290-320 nm) & \\
\hline$\overline{\text { Symbol }}$ & Meaning & Unit \\
\hline$a_{\mathrm{CDOM}}$ & Absorption coefficient of CDOM & $\mathrm{m}^{-1}$ \\
\hline$a_{\mathrm{CDOM}}^{\prime}$ & $\begin{array}{l}\text { Absorption coefficient of } \mathrm{CDOM} \text { based on } \mathrm{GF} / \mathrm{F} \\
\text { filtration }\end{array}$ & $\mathrm{m}^{-1}$ \\
\hline$a_{\mathrm{CDOM}, 330}$ & Absorption coefficient of CDOM at $330 \mathrm{~nm}$ & $\mathrm{~m}^{-1}$ \\
\hline$a_{\mathrm{CDOM}, \mathrm{alga}}$ & Absorption coefficient of algal-derived CDOM & $\mathrm{m}^{-1}$ \\
\hline$a_{\mathrm{CDOM}, \text { medium }}$ & Absorption coefficient of medium-based CDOM & $\mathrm{m}^{-1}$ \\
\hline$a_{\text {nap }}$ & Absorption coefficient of non-algal particles & $\mathrm{m}^{-1}$ \\
\hline$a_{\mathrm{p}}$ & Absorption coefficient of total particles & $\mathrm{m}^{-1}$ \\
\hline$a_{\mathrm{p}, 443}$ & Absorption coefficient of total particles at $443 \mathrm{~nm}$ & $\mathrm{~m}^{-1}$ \\
\hline$a_{\text {phy }}$ & Absorption coefficient of ice algal pigment & $\mathrm{m}^{-1}$ \\
\hline$a_{\text {phy }, 443}$ & Absorption coefficient of ice algal pigment at $443 \mathrm{~nm}$ & $\mathrm{~m}^{-1}$ \\
\hline$a_{\mathrm{t}}$ & Absorption coefficient of the sum of $a_{\text {cdom }}, a_{\mathrm{p}}$ and $a_{\mathrm{w}}$ & $\mathrm{m}^{-1}$ \\
\hline$a_{\mathrm{w}}$ & Absorption coefficient of pure water & \\
\hline$A$ & Clearance area of filters for retaining particles & $\mathrm{m}^{2}$ \\
\hline$b$ & Scattering coefficient of particles & $\mathrm{m}^{-1}$ \\
\hline$\beta$ & Pathlength amplification factor & unitless \\
\hline
\end{tabular}




\begin{tabular}{|c|c|c|}
\hline$c$ & Beam attenuation coefficient & $\mathrm{m}^{-1}$ \\
\hline$\lambda$ & Wavelength & $\mathrm{nm}$ \\
\hline$\lambda_{50 \% \mathrm{~T}}$ & $50 \%$-transmittance wavelength & $\mathrm{nm}$ \\
\hline$L$ & Light pathlength of irradiation cells & $\mathrm{m}$ \\
\hline$O D$ & Optical density & unitless \\
\hline$O D_{\text {blank }}$ & Optical density of blank GF/F filter & unitless \\
\hline$O D_{\mathrm{CDOM}}$ & Optical density of CDOM & unitless \\
\hline$O D_{\mathrm{f}}$ & Optical density of particles & unitless \\
\hline$P_{\mathrm{CDOM}, \lambda}$ & $\begin{array}{l}\text { Rate of CO photoproduction from CDOM in } \\
\text { bottommost } 10-\mathrm{cm} \text { sea ice }\end{array}$ & $\mu \mathrm{mol} \mathrm{CO} \mathrm{m}{ }^{-2} \mathrm{~d}^{-1} \mathrm{~nm}^{-1}$ \\
\hline$P_{\mathrm{POM}, \lambda}$ & $\begin{array}{l}\text { Rate of CO photoproduction from POM in } \\
\text { bottommost } 10-\mathrm{cm} \text { sea ice }\end{array}$ & $\mu \mathrm{mol} \mathrm{CO} \mathrm{m}{ }^{-2} \mathrm{~d}^{-1} \mathrm{~nm}^{-1}$ \\
\hline$P_{\mathrm{CDOM}, \text { alga }, \lambda}$ & $\begin{array}{l}\text { CO photoproduction rate from algal-derived CDOM } \\
\text { in culture filtrates }\end{array}$ & $\mathrm{mol} \mathrm{CO} \mathrm{s}{ }^{-1} \mathrm{~nm}^{-1}$ \\
\hline$P_{\mathrm{CDOM}, \mathrm{medium}, \lambda}$ & $\begin{array}{l}\text { Rate of CO photoproduction from medium-based } \\
\text { CDOM in culture filtrates }\end{array}$ & $\operatorname{mol~CO~s}{ }^{-1} \mathrm{~nm}^{-1}$ \\
\hline$P_{\mathrm{CDOM}, \mathrm{t}, \lambda}$ & $\begin{array}{l}\text { Rate of } \mathrm{CO} \text { photoproduction from total CDOM in } \\
\text { culture filtrates }\end{array}$ & $\operatorname{mol~CO~s}{ }^{-1} \mathrm{~nm}^{-1}$ \\
\hline$\Phi$ & CO apparent quantum yield (AQY) & mol CO (mol photons $)^{-1}$ \\
\hline$\Phi_{\mathrm{CDOM}, \lambda}$ & CO AQY for CDOM & mol CO (mol photons) $)^{-1}$ \\
\hline$\Phi_{\mathrm{CDOM}, \mathrm{alga}, \lambda}$ & CO AQY for algal-derived CDOM in culture filtrate & mol CO (mol photons $)^{-1}$ \\
\hline$\Phi_{\mathrm{CDOM}, \text { medium }, \lambda}$ & $\begin{array}{l}\text { CO AQY for medium-based CDOM in medium } \\
\text { control }\end{array}$ & mol CO (mol photons $)^{-1}$ \\
\hline$\Phi_{\mathrm{CDOM}, \mathrm{t}, \lambda}$ & CO AQY for total CDOM in culture filtrate & mol CO (mol photons) $)^{-1}$ \\
\hline$\Phi_{\mathrm{p}, \lambda}$ & CO AQY for particles & mol CO (mol photons $)^{-1}$ \\
\hline $\bar{\Phi}$ & Solar irradiance spectrum-weighted mean $\Phi$ & mol CO (mol photons) $)^{-1}$ \\
\hline $\bar{\Phi}_{\mathrm{CDOM}}$ & $\begin{array}{l}\text { Solar irradiance spectrum-weighted mean } \Phi \text { for } \\
\text { CDOM }\end{array}$ & mol CO (mol photons) $)^{-1}$ \\
\hline $\bar{\Phi}_{\mathrm{p}}$ & $\begin{array}{l}\text { Solar irradiance spectrum-weighted mean } \Phi \text { for } \\
\text { particles }\end{array}$ & mol CO (mol photons) $)^{-1}$ \\
\hline$Q_{\lambda}$ & $\begin{array}{l}\text { Photon flux just below the frontal quartz window of } \\
\text { irradiation cells }\end{array}$ & mol photons $\mathrm{m}^{-2} \mathrm{~s}^{-1} \mathrm{~nm}^{-1}$ \\
\hline$Q_{0, \lambda}$ & Modeled surface solar photon flux & mol photons $\mathrm{m}^{-2} \mathrm{~h}^{-1} \mathrm{~nm}^{-1}$ \\
\hline$Q_{0, \lambda}^{\prime}$ & $\begin{array}{l}\text { In-ice spectral solar photon flux at the depth of } 10 \mathrm{~cm} \\
\text { from the ice-water interface }\end{array}$ & mol photons $\mathrm{m}^{-2} \mathrm{~d}^{-1} \mathrm{~nm}^{-1}$ \\
\hline$Q_{\mathrm{a}, \lambda}$ & Photons absorbed by CDOM or CDOM plus particles & mol photons $\mathrm{m}^{-2} \mathrm{~s}^{-1} \mathrm{~nm}^{-1}$ \\
\hline
\end{tabular}


$\overline{Q_{\mathrm{a}(\mathrm{CDOM}, \mathrm{algal}, \lambda}}$ Photons absorbed by algal-derived CDOM in culture mol photons $\mathrm{m}^{-2} \mathrm{~s}^{-1} \mathrm{~nm}^{-1}$ filtrates

$Q_{\mathrm{a}(\mathrm{CDOM}, \text { medium }) \lambda}$ Photons absorbed by medium-based CDOM in culture mol photons $\mathrm{m}^{-2} \mathrm{~s}^{-1} \mathrm{~nm}^{-1}$ filtrates

$Q_{\mathrm{a}(\mathrm{CDOM}, \mathrm{t}), \lambda} \quad$ Photons absorbed by total CDOM in culture filtrates mol photons $\mathrm{m}^{-2} \mathrm{~s}^{-1} \mathrm{~nm}^{-1}$

$R_{\mathrm{POM} / \mathrm{CDOM}} \quad$ Ratio of $\mathrm{CO}$ photoproduction from particles to that unitless from CDOM (i.e. $\left.P_{\mathrm{POM}, \lambda}: P_{\mathrm{CDOM}, \lambda}\right)$

$S \quad$ Cross-section area of irradiation cells $\quad \mathrm{m}^{2}$

$V \quad$ Filtered volume of water samples through GF/F filters $\mathrm{m}^{3}$

$Z \quad$ Light pathlength of the bottommost $10-\mathrm{cm}$ sea ice $\mathrm{m}$ 
Table A2 Fitted parameters for linear regression $\left(\mathrm{y}=a^{*} \mathrm{x}+b\right)$ between measured and predicted CO photoproduction for the simple and quasiexponential CO AQY models. $\mathrm{R}^{2}$ : coefficient of determination; nRMSE: normalized root-mean-squared error; ND: no data available (i.e. the model does not converge).

\begin{tabular}{|c|c|c|c|c|c|c|c|c|}
\hline \multirow{3}{*}{ Ice algae } & \multicolumn{4}{|c|}{ Simple exponential model } & \multicolumn{4}{|c|}{ Quasi-exponential model } \\
\hline & $a$ & $b\left(\times 10^{-11}\right)$ & $\mathrm{R}^{2}$ & nRMSE (\%) & $a$ & $b\left(\times 10^{-11}\right)$ & $\mathrm{R}^{2}$ & nRMSE (\%) \\
\hline & \multicolumn{8}{|c|}{ CDOM (EP) } \\
\hline P. taeniata & 1.01 & -1.66 & 0.997 & 5 & ND & ND & ND & ND \\
\hline A. septentrionalis & 1.02 & -2.94 & 0.998 & 6 & ND & ND & ND & ND \\
\hline N. frigida & 0.99 & 0.46 & 0.996 & 6 & 0.98 & 1.95 & 0.993 & 8 \\
\hline \multirow[t]{2}{*}{ NIAA } & 1.02 & -4.48 & 0.998 & 4 & ND & ND & ND & ND \\
\hline & \multicolumn{8}{|c|}{ CDOM (SP) } \\
\hline P. taeniata & 1.02 & -8.27 & 0.997 & 5 & 1.00 & 0.26 & 0.999 & 3 \\
\hline A. septentrionalis & 1.02 & -0.51 & 0.999 & 5 & ND & ND & ND & ND \\
\hline N. frigida & 0.99 & 0.75 & 0.998 & 4 & ND & ND & ND & ND \\
\hline \multirow[t]{2}{*}{ NIAA } & 1.02 & -15.1 & 0.995 & 6 & ND & ND & ND & ND \\
\hline & \multicolumn{8}{|c|}{ Particles (EP) } \\
\hline P. taeniata & ND & ND & ND & ND & 1.04 & -23.5 & 0.991 & 8 \\
\hline A. septentrionalis & ND & ND & ND & ND & 1.04 & -7.50 & 0.994 & 6 \\
\hline
\end{tabular}




\begin{tabular}{lllllllll}
\hline $\begin{array}{l}N . \text { frigida } \\
\text { NIAA }\end{array}$ & ND & ND & ND & ND & 1.03 & -2.37 & 0.991 & 8 \\
& ND & ND & ND & ND & 1.04 & -17.7 & 0.991 & 7 \\
\multirow{2}{*}{$\begin{array}{l}\text { P. taeniata } \\
\text { A. septentrionalis }\end{array}$} & ND & ND & ND & ND & 0.98 & 7.00 & 0.995 & 7 \\
NIAA & ND & ND & ND & 1.01 & -2.16 & 0.997 & 4 \\
& ND & ND & ND & ND & 1.03 & -7.30 & 0.995 & 6 \\
\hline
\end{tabular}


Table A3 Values of $a_{\mathrm{p}, 443}, a_{\text {cdom,330 }}^{\prime}$ and [DOC] after irradiation and in dark controls. Dark: dark controls; light: after irradiation under cutoff filter WG 280 (i.e. full spectrum); EP: exponential phase; SP: senescent phase; ND: no data available.

\begin{tabular}{|c|c|c|c|c|c|c|c|c|}
\hline & \multicolumn{2}{|c|}{ P. taeniata } & \multicolumn{2}{|c|}{ A. septentrionalis } & \multicolumn{2}{|c|}{ N. frigida } & \multicolumn{2}{|c|}{ NIAA } \\
\hline & dark & light & dark & light & dark & light & dark & light \\
\hline & \multicolumn{8}{|c|}{$a_{\mathrm{p}, 443}\left(\mathrm{~m}^{-1}\right)$} \\
\hline $\mathrm{EP}$ & 0.93 & 0.94 & 1.10 & 1.08 & 0.29 & 0.29 & 1.33 & 1.32 \\
\hline \multirow[t]{2}{*}{$\mathrm{SP}$} & 0.85 & 0.84 & 0.68 & 0.68 & ND & ND & 0.13 & 0.13 \\
\hline & \multicolumn{8}{|c|}{$a_{\mathrm{CDOM}, 330}^{\prime}\left(\mathrm{m}^{-1}\right)$} \\
\hline $\mathrm{EP}$ & 0.11 & 0.11 & 0.08 & 0.08 & 0.06 & 0.06 & 0.22 & 0.23 \\
\hline \multirow[t]{2}{*}{ SP } & 0.08 & 0.10 & 0.09 & 0.09 & ND & ND & 0.07 & 0.08 \\
\hline & \multicolumn{8}{|c|}{$[\mathrm{DOC}]\left(\mu \mathrm{mol} \mathrm{L}{ }^{-1}\right)$} \\
\hline $\mathrm{EP}$ & 26.7 & 25.2 & 16.7 & 16.3 & 22.5 & 20.8 & 36.7 & 36.7 \\
\hline SP & 53.3 & 51.7 & 43.3 & 44.2 & ND & ND & 25.0 & 26.7 \\
\hline
\end{tabular}

\section{Equations A1-A8 (derivation of CO AQY for algal-derived CDOM)}

This derivation is based on the approach identical to that published by Song et al. (2013). In culture filtrates containing algal-derived CDOM and CDOM originally existing in the $\mathrm{f} / 2$ medium:

$P_{\mathrm{CDOM}, \mathrm{t}, \lambda}=P_{\mathrm{CDOM}, \mathrm{alga}, \lambda}+P_{\mathrm{CDOM}, \text { medium }, \lambda}$

$P_{\mathrm{CDOM}, \mathrm{t}, \lambda}=\Phi_{\mathrm{CDOM}, \mathrm{t}, \lambda} \times Q_{\mathrm{a}(\mathrm{CDOM}, \mathrm{t}), \lambda}$

$P_{\mathrm{CDOM}, \text { alga }, \lambda}=\Phi_{\mathrm{CDOM}, \mathrm{alga}, \lambda} \times Q_{\mathrm{a}(\mathrm{CDOM}, \mathrm{alga}), \lambda}$ (A3)

$P_{\mathrm{CDOM}, \text { medium }, \lambda}=\Phi_{\mathrm{CDOM}, \text { medium }, \lambda} \times Q_{\mathrm{a}(\mathrm{CDOM}, \text { medium }), \lambda}$

where

$P_{\mathrm{CDOM}, \mathrm{t}, \lambda}:$ total $\mathrm{CO}$ photoproduction from algal-derived CDOM and CDOM added from the $\mathrm{f} / 2$ medium ( $\left.\mathrm{mol} \mathrm{CO} \mathrm{s} \mathrm{nm}^{-1}\right)$;

$P_{\mathrm{CDOM}, a l g a, \lambda}: \mathrm{CO}$ photoproduction from algal-derived $\mathrm{CDOM}\left(\mathrm{mol} \mathrm{CO} \mathrm{s}^{-1} \mathrm{~nm}^{-1}\right)$; 
$P_{\mathrm{CDOM}, \text { medium }, \lambda}: \mathrm{CO}$ photoproduction from $\mathrm{CDOM}$ added from the $\mathrm{f} / 2$ medium (mol $\left.\mathrm{CO} \mathrm{s}^{-1} \mathrm{~nm}^{-1}\right)$

$\Phi_{\mathrm{CDOM}, \mathrm{t}, \lambda}: \mathrm{CO}$ AQY for total CDOM (i.e. algal-derived CDOM plus medium-based $\mathrm{CDOM})$ determined with culture filtrates (mol CO (mol photons $)^{-1}$ );

$\Phi_{\mathrm{CDOM}, \mathrm{alga}, \lambda}: \mathrm{CO}$ AQY for algal-derived CDOM (mol CO (mol photons) $\left.{ }^{-1}\right)$;

$\Phi_{\mathrm{CDOM}, \text { medium }, \lambda}$ : CO AQY for medium-based CDOM determined with the medium control (mol CO (mol photons $\left.)^{-1}\right)$;

$Q_{\mathrm{a}(\mathrm{CDOM}, \mathrm{t}), \lambda}$ : flux of photons absorbed by total CDOM (mol photons s ${ }^{-1}$ );

$Q_{\mathrm{a}(\mathrm{CDOM}, \mathrm{alga}), \lambda}$ : flux of photons absorbed by algal-derived CDOM (mol photons s${ }^{-1}$ );

$Q_{\mathrm{a}(\mathrm{CDOM}, \text { medium) }, \lambda}$ : flux of photons absorbed by medium-based CDOM (mol photons $\mathrm{s}^{-1}$ ).

The fluxes of absorbed photons can be computed according to Hu et al. (2002):

$Q_{\mathrm{a}(\mathrm{CDOM}, \mathrm{t}), \lambda}=Q_{\lambda} \times S \times\left(\left(a_{\mathrm{CDOM}, \text { alga }, \lambda}+a_{\mathrm{CDOM}, \text { medium }, \lambda}\right) / a_{\mathrm{t}, \lambda}\right) \times[1-$ $\left.\exp \left(-a_{\mathrm{t}, \lambda} \times L\right)\right]$

$Q_{\mathrm{a}(\mathrm{CDOM}, \mathrm{alga}), \lambda}=Q_{\lambda} \times S \times\left(a_{\mathrm{CDOM}, \mathrm{alga}, \lambda} / a_{\mathrm{t}, \lambda}\right) \times\left[1-\exp \left(-a_{\mathrm{t}, \lambda} \times L\right)\right]$ (A6)

$Q_{\mathrm{a}(\mathrm{CDOM}, \text { medium }, \lambda}=Q_{\lambda} \times \mathrm{S} \times\left(a_{\mathrm{CDOM}, \text { medium }, \lambda} / a_{\mathrm{t}, \lambda}\right) \times\left[1-\exp \left(-a_{\mathrm{t}, \lambda} \times L\right)\right]$ (A7)

where

$Q_{\lambda}$ : photon flux just below the frontal quartz window of the irradiation cell (mol photons $\mathrm{m}^{-2} \mathrm{~s}^{-1}$ );

$a_{\mathrm{CDOM}, \text { alga, } \lambda}:$ absorption coefficient of algal-derived CDOM $\left(\mathrm{m}^{-1}\right)$;

$a_{\mathrm{CDOM}, \text { medium, } \lambda}:$ absorption coefficient of medium-based CDOM ( $\left.\mathrm{m}^{-1}\right)$;

$a_{\mathrm{CDOM}, \mathrm{t}, \lambda}$ : absorption coefficient of total CDOM plus that of pure water $\left(\mathrm{m}^{-1}\right)$;

$L$ : pathlength of the irradiation cell (m);

$S:$ cross-section area of the irradiation cell $\left(\mathrm{m}^{2}\right)$;

Substituting Eqs. A2) to A7 into Eq. A1 and rearranging it give

$$
\begin{gathered}
\Phi_{\mathrm{CDOM}, \text { alga }, \lambda}= \\
\Phi_{\mathrm{CDOM}, \mathrm{t}, \lambda}+\left(\Phi_{\mathrm{CDOM}, \mathrm{t}, \lambda}-\Phi_{\mathrm{CDOM}, \text { medium }, \lambda}\right) \times\left(a_{\mathrm{CDOM}, \text { medium }, \lambda} / a_{\mathrm{CDOM}, \mathrm{alga}, \lambda}\right)
\end{gathered}
$$




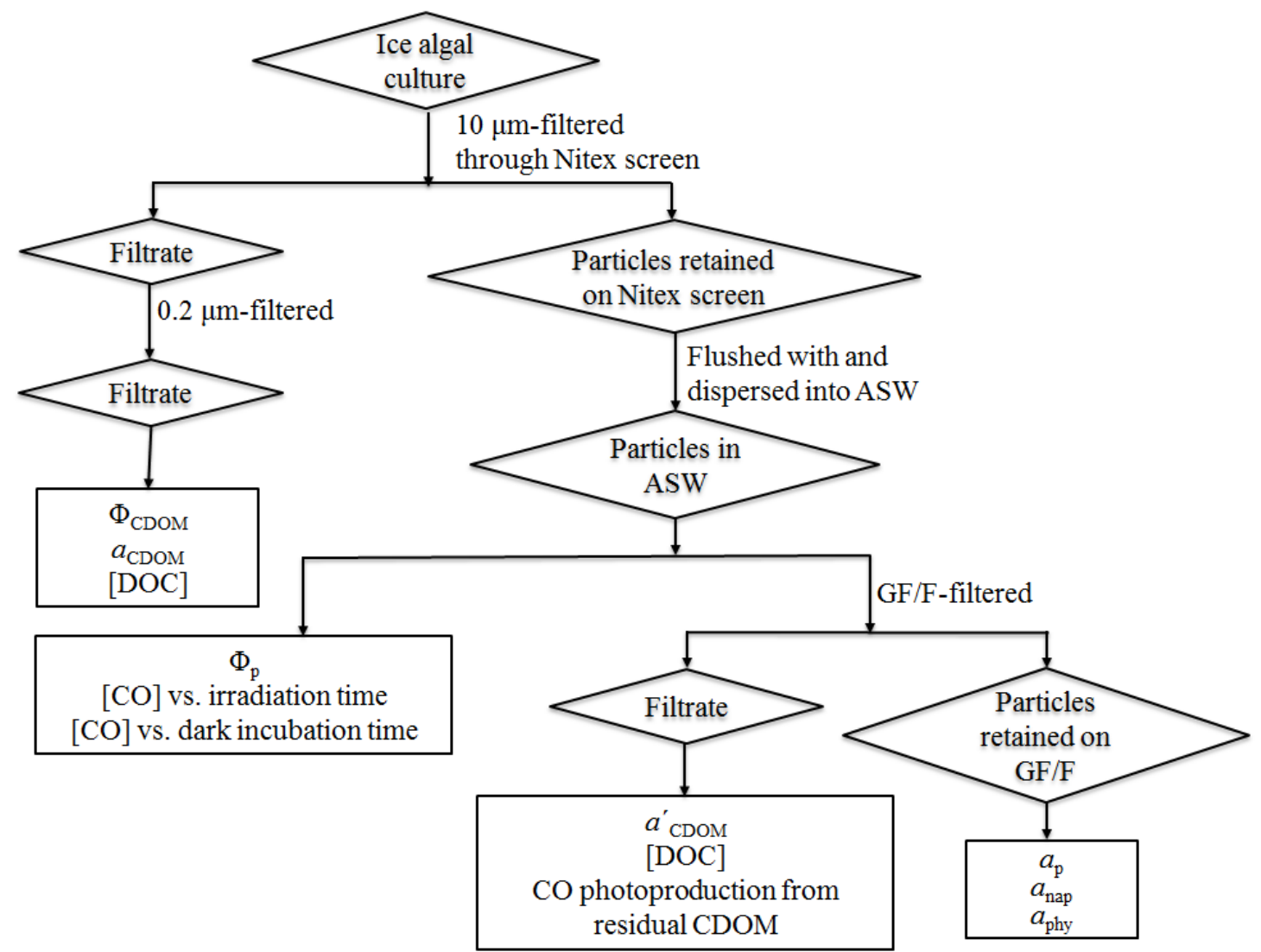

Fig. A1. Flow chart of the main procedures of sample collection and processing. Diamonds denote samples obtained at different sample processing stages, rectangles designate parameters measured, and text next to arrows indicates sample manipulations. See Table A1 for definitions of symbols and abbreviations. 
A)

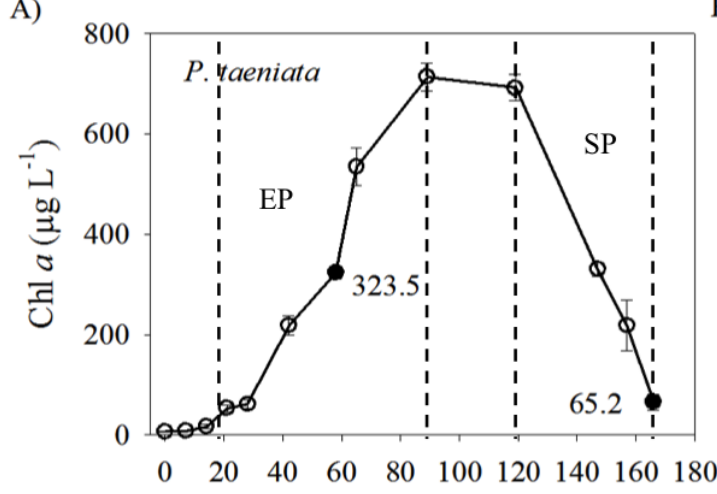

C)

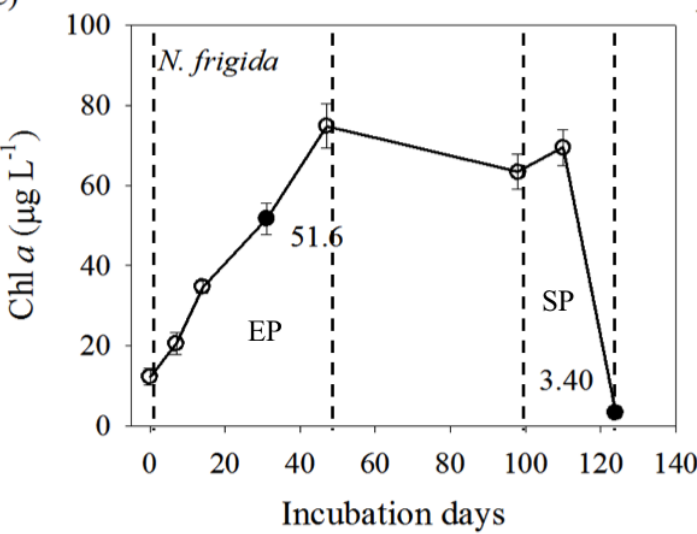

B)

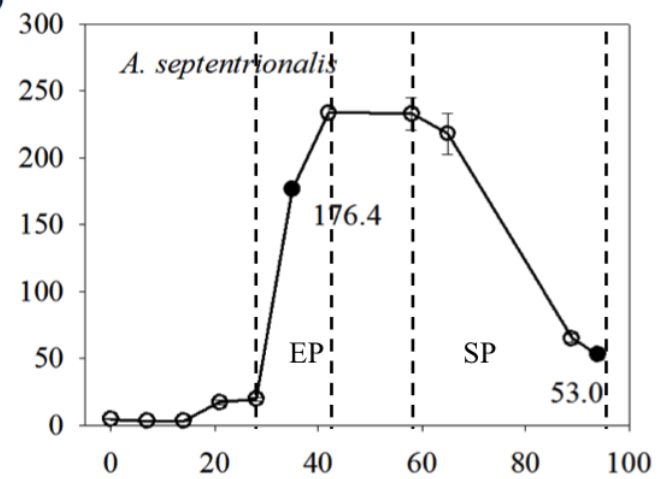

D)

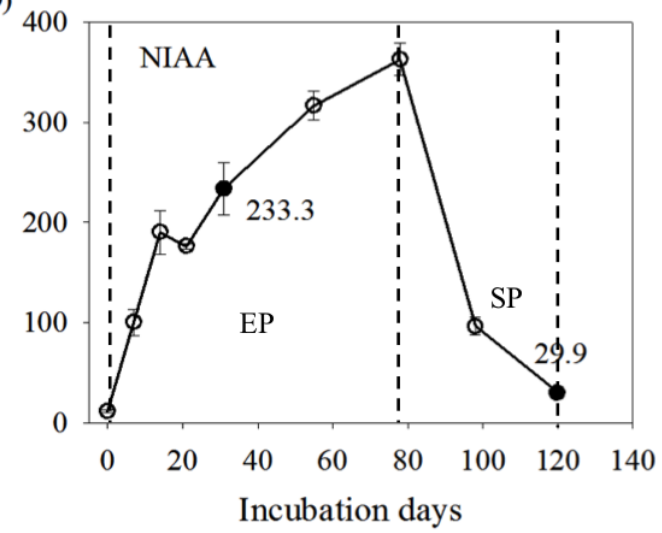

Fig. A2. Temporal progression of $[\mathrm{Chl} a]$ in ice algal cultures. Solid points in each panel denote collecting times of DOM and particle samples for CO photoproduction experiments. 


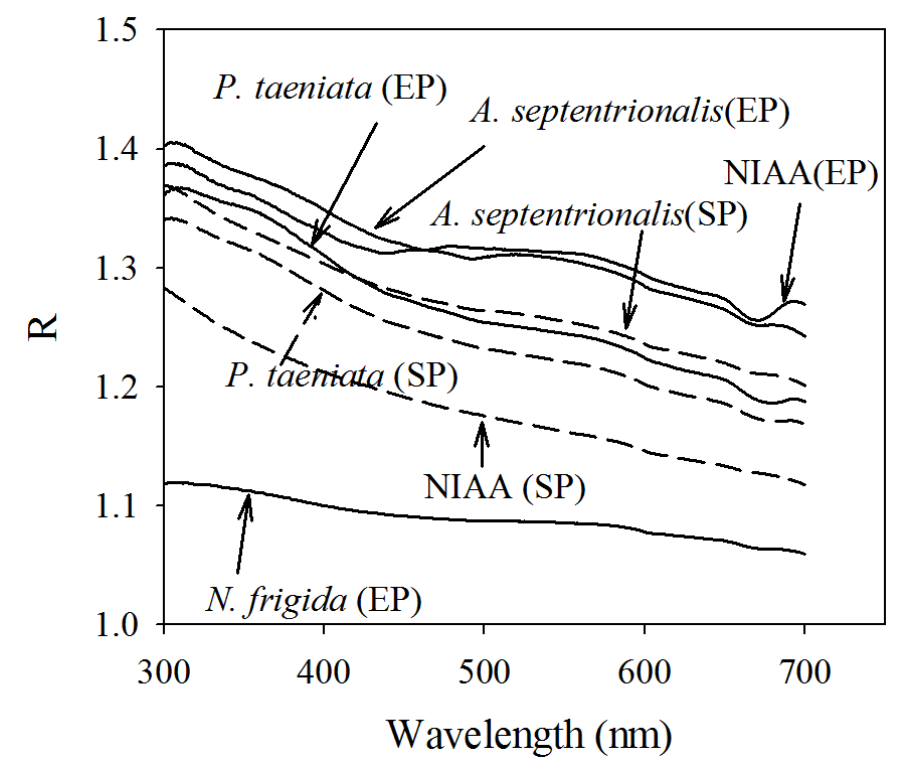

Fig. A3. Particle scattering effect expressed by $R$ as a function of wavelength. $R$ denotes the ratio of the number of absorbed photons calculated from $\mathrm{Hu}$ et al. (2002) (Eq. 3 in the main text) to that modeled using Monte Carlo simulation. Refer to Song et al. (2013) for details in the calculation of $R$. 